\title{
Evaluating Himawari-8 Cloud Products Using Shipborne and CALIPSO Observations: Cloud-Top Height and Cloud-Top Temperature
}

\author{
YI HUANG \\ University of Melbourne, and Australian Research Council Centre of Excellence for Climate Extremes (CLEX), \\ University of Melbourne, Melbourne, Australia \\ STEVEn Siems ANd Michael Manton \\ Monash University, Melbourne, Victoria, Australia
}

Alain Protat, Leon Majewski, AND Hanh NGUyen

Australian Bureau of Meteorology, Melbourne, Victoria, Australia

(Manuscript received 21 December 2018, in final form 7 August 2019)

\begin{abstract}
Cloud-top height $(\mathrm{CTH})$ and cloud-top temperature (CTT) retrieved from the Himawari-8 observations are evaluated using the active shipborne radar-lidar observations derived from the 31-day Clouds, Aerosols, Precipitation Radiation and Atmospheric Composition over the Southern Ocean (CAPRICORN) experiment in 2016 and 1-yr observations from the spaceborne Cloud-Aerosol Lidar with Orthogonal Polarization (CALIOP) cloud product over a large sector of the Southern Ocean. The results show that the Himawari-8 CTH (CTT) retrievals agree reasonably well with both the shipborne estimates, with a correlation coefficient of $0.837(0.820)$, a mean bias error of $0.226 \mathrm{~km}\left(-2.526^{\circ} \mathrm{C}\right)$, and an RMSE of $1.684 \mathrm{~km}\left(10.069^{\circ} \mathrm{C}\right)$. In the comparison with CALIOP, the corresponding quantities are found to be $0.786(0.480),-0.570 \mathrm{~km}\left(1.343^{\circ} \mathrm{C}\right)$, and $2.297 \mathrm{~km}\left(25.176^{\circ} \mathrm{C}\right)$. The Himawari-8 CTH (CTT) generally falls between the physical CTHs observed by CALIOP and the shipborne radar-lidar estimates. However, major systematic biases are also identified. These errors include (i) a low (warm) bias in CTH (CTT) for warm liquid cloud type, (ii) a cold bias in CTT for supercooled liquid water cloud type, (iii) a lack of $\mathrm{CTH}$ at $\sim 3 \mathrm{~km}$ that does not have a corresponding gap in CTT, (iv) a tendency of misclassifying some low-/mid-top clouds as cirrus and overlap cloud types, and (v) a saturation of CTH $(\mathrm{CTT})$ around $10 \mathrm{~km}\left(-40^{\circ} \mathrm{C}\right)$, particularly for cirrus and overlap cloud types. Various challenges that underpin these biases are also explored, including the potential of parallax bias, low-level inversion, and cloud heterogeneity.
\end{abstract}

\section{Introduction}

Large biases in the radiation budget over the Southern Ocean (SO) continue to exist in both climate models and reanalysis products, which are attributed to a poor understanding of clouds and precipitation in this region (Trenberth and Fasullo 2010; Grise et al. 2015). Due to the remote nature of the SO, satellite-derived products are crucial for understanding of the SO climate system, and for the evaluation and continued improvement of global models. The polar-orbiting A-Train constellation (Stephens et al. 2002), in particular, has underpinned much of our current understanding of cloud, aerosol,

Corresponding author: Yi Huang, yi.huang4@unimelb.edu.au precipitation, and radiation research over this region (e.g., Bennartz 2007; Hu et al. 2010; Huang et al. 2012a,b, $2015,2016)$, not only due to their global coverage but also to the vertical profiling capacity of CloudSat and the Cloud-Aerosol Lidar and Infrared Pathfinder Satellite Observation (CALIPSO). Despite these advances, a known limitation of polar-orbiting satellites is that they can only scan the same area twice a day (except for polar regions) and usually at the same local times. Thus, they are unable to monitor the temporal evolution and contribute to nowcasting of fast developing severe weather events and rapidly evolving convective storms.

The advent of the Himawari- 8 geostationary satellite represented a major revolution in spaceborne weather monitoring capacities over the Asia-Oceania region, 
including a large portion of the SO. Launched by the Japanese Meteorological Agency and becoming operational in July 2015, this next-generation satellite provides a significant increase in the spatial $(2-5 \mathrm{~km})$ and temporal $(10 \mathrm{~min})$ resolution of imagery. With the Advanced Himawari Imager (AHI) aboard, the unprecedented number of channels of Himawari allows for aerosol and cloud retrievals that are in principle more accurate than those from other geostationary satellite. The essentially continuous nature of Himawari-8 observations makes the data ideal for investigating the temporal and spatial variability of evolving weather systems within its field of view (FOV). These observations also present significant benefits for process-oriented model evaluation and climate studies.

Among the retrieved cloud properties, an accurate representation of cloud-top height $(\mathrm{CTH})$ and cloud-top temperature (CTT) is critical for determining the impact of clouds on Earth's radiation budget. From a passive remote sensing perspective, three basic approaches have commonly been used to retrieve CTH/CTT (Hamann et al. 2014, and references therein). The first approach is the so-called "radiance fitting" method. This method utilizes a radiative transfer model to calculate the radiance at the top of the atmosphere, given an atmospheric temperature and humidity profile as well as the assumed (or explicitly derived) cloud cover and spectral cloud emissivity (e. g., Roebeling et al. 2006). This method is known to overestimate (underestimate) CTT (CTH) if the FOV is partially cloud filled or contains optically thin clouds. The second method is the optimal estimation (OE) method (e.g., Rodgers 2000). The basic principle of the OE method is to maximize the probability of the retrieved state, conditional on the value of the measurements and any a priori knowledge. Essential outputs of the OE method are a measure of the model fit to the observations via a cost function. The third approach is named the "radiance ratioing" (also named split window or $\mathrm{CO}_{2}$ slicing) method (e.g., Chahine 1974). The method relies on the strong temperature sensitivity of the channels within the broad $15-\mu \mathrm{m} \mathrm{CO}_{2}$ absorption band. The technique is based on the atmosphere becoming more opaque resulting from $\mathrm{CO}_{2}$ absorption as the wavelength increases from 13.3 to $15 \mu \mathrm{m}$, thereby causing radiances obtained from these spectral bands to be sensitive to a different layer in the atmosphere. This algorithm is found to overcome some deficiencies of the radiance fitting method in partially cloudy and semitransparent cloud regimes (e.g., Menzel et al. 2008).

Despite the significant progress that has been achieved over the past decades, some challenges remain in the interpretation of the measured radiance. Major bottleneck issues most relevant to $\mathrm{CTH} / \mathrm{CTT}$ include (but are not limited to) 1) the retrieval problem is not fully constrained by observations-dominant information originates from the cloud top thus it may not represent the complex structure of entire cloud layer/layers; 2) temperature inversions - the monotonic relationship between temperature and height/pressure is no longer valid so the conversion can be ambiguous; 3) limited vertical resolution of the assumed atmospheric temperature profiles that is needed to accurately represent the temperature inversion. As a result, large uncertainties remain in the retrievals for broken clouds, thin cirrus layers and multilayer clouds (e.g., Hamann et al. 2014). Comparison and validation studies are much needed to appreciate the strengths and limitations of algorithms and their retrieval products over different geographical regions.

In addition to the abovementioned issues, specific challenges are presented by the SO region itself. Operational networks and in situ reference measurements that can be used to evaluate satellite retrievals are extremely sparse over this region. The SO features some of the most extreme conditions in the world (e.g., pristine air mass, strong winds, higher frequency of sea spray), making the accuracy of many retrieval products potentially questionable.

In recent years, several observational programs have been taking place over the SO in response to the need to better understand processes and interaction between clouds, aerosols, and radiation over this region. The Clouds, Aerosols, Precipitation, Radiation and Atmospheric Composition over the Southern Ocean (CAPRICORN) experiment, led by the Australian Bureau of Meteorology (BoM), is one of these efforts (Mace and Protat 2018a). The CAPRICORN-2016 (Phase I) experiment was conducted with the Australian Marine National Facility (MNF) Research Vessel (R/V) Investigator from 14 March to 16 April 2016. The Investigator was equipped with a suite of state-of-theart active and passive instruments, making a comprehensive set of measurements including the first-ever concurrent observations on cloud and precipitation with a $95-\mathrm{GHz}$ stabilized cloud radar, a cloud and aerosol backscatter lidar, a micro rain radar, and a microwave radiometer, over the lower latitudes of the Australian sector of the Southern Ocean $\left(42^{\circ}-53^{\circ} \mathrm{S}, 140^{\circ}-152^{\circ} \mathrm{E}\right)$. Despite the relatively short sampling period, the observations collected during the cruise provide a unique opportunity to evaluate cloud retrieval products from Himawari-8 and other spaceborne platforms. These shipborne observations are particularly skillful in detecting low clouds, especially those lying within the 
lowest $1 \mathrm{~km}$, which is challenging for active spaceborne sensors.

While useful as "ground truth," it is important to note that potential biases can be caused by the different sensitivities of the shipborne sensors and viewing geometry (from ground up). The received power by the cloud radar or lidar is affected by the particle size observed such that the radar is sensitive to large particles and the lidar is sensitive to small particles. Also, extinction due to clouds at lidar wavelengths is greater than extinction for the radar. Therefore, these shipborne sensors have difficulties in detecting thin ice clouds in multilayer situations with low clouds (lidar fully attenuated and cloud radar not sensitive enough due to thin cirrus optical depth, distance from ground, and attenuation through the low clouds) and cloud tops heights in precipitating profiles (lidar extinguished and cloud radar attenuated, therefore underestimating cloud-top height). To mitigate potential biases of the shipborne measurements in the comparisons, a spaceborne reference dataset is also used in our study. The Cloud-Aerosol Lidar with Orthogonal Polarization (CALIOP) on CALIPSO is arguably the spaceborne sensor most sensitive to the presence of clouds in the atmosphere, thus having the potential for establishing a firm understanding of the cloud detection limit for cloud retrieval methods based on other spaceborne platforms.

The aim of this study is to evaluate cloud-top height and cloud-top temperature retrievals from Himawari-8 satellite using shipborne measurements from CAPRICORN and other spaceborne products. Microphysical and optical properties will be examined in a second paper.

\section{Data and methodology}

\section{a. Himawari-8 cloud products}

The Himawari-8 cloud-top height and cloud-top temperature (hereafter CTH and CTT) retrievals evaluated in this study are provided by the BoM using the Advanced Baseline Imager (ABI) Cloud Height Algorithm (ACHA; Heidinger 2011) —an algorithm originally developed at the National Oceanic and Atmospheric Administration (NOAA) for the ABI aboard the Geostationary Operational Environmental Satellite-R series (now named GOES-16). The ACHA represents a merger of current operational CTH algorithms run by the National Environmental Satellite, Data, and Information Service on the Polar Orbiting Environmental Satellite (POES) and GOES imagers. Unlike the GOES-NOP imager or the POES imager that have fewer channels, the AHI on Himawari-8 provides the 13.3- $\mu \mathrm{m} \mathrm{CO}_{2}$ absorption channel coupled with multiple longwave infrared (IR) windows (10.4, 11.2 , and $12.4 \mu \mathrm{m}$ ), allowing an opportunity to combine the sensitivity to $\mathrm{CTH}$ from the $\mathrm{CO}_{2}$ channel with the sensitivity to cloud microphysics from the window channels. Taking advantage of the multichannel information provided by the AHI (as for the ABI on GOES-16), the ACHA applies a $\mathrm{CO}_{2}$ /split-window approach to derive CTH information simultaneously with cloud microphysics information, which avoids making assumptions on cloud microphysics for retrieving CTH. For Himawari-8, CTH and CTT are retrieved at a spatial resolution of $2 \mathrm{~km}$ and a temporal resolution of $10 \mathrm{~min}$. The retrieval of CTH also requires interpolated environmental variables, such as temperature and water vapor profiles, which are derived from a limited area model of the Australian Community Climate and Earth-System Simulator (ACCESS) operational numerical weather prediction (NWP) system used by the BoM (Puri et al. 2013). Other required variables that are not available from ACCESS (ozone, total precipitable water, etc.) are derived from the Global Forecast System (GFS) produced by the National Centers for Environmental Prediction (NCEP).

In addition to evaluating CTH and CTT, the Himawari-8 cloud type product (Pavolonis 2010) derived from four AHI infrared channels $(7.3,8.6,11.2$, and $12.4 \mu \mathrm{m}$ ) is also employed to help understand the origin of retrieval biases. In lieu of brightness temperature differences, the cloud type algorithm makes use of the effective absorption optical depth ratios to perform the spectral tests and make classifications of nine cloud types: FOG, warm liquid water cloud (WL), supercooled liquid water (SLW), mixed phase (MIXED), opaque ice (ICE), CIRRUS (e.g., semitransparent ice clouds), OVERLAP (with semitransparent upper layer), OVERSHOOTING, and uncertain (UN).

As a general rule, the radiances observed by a passive imager such as AHI are linearly weighted averages of the layers within the vertical temperature profile of the atmosphere. Therefore, the contribution of each layer of the atmosphere to the observed radiance can be described by a weighting function for each channel, which varies with the viewing angle and atmospheric state. As such, the CTH retrievals from these radiances are expected to be generally lower and warmer than the physical CTH that is measured by active spaceborne sensors, such as CALIPSO (e.g., Sherwood et al. 2004; Minnis et al. 2008; Stubenrauch et al. 2010; Taylor et al. 2017). In addition, passive imagers are known to be less sensitive to 
(a) Himawari-8 Cloud-top Height
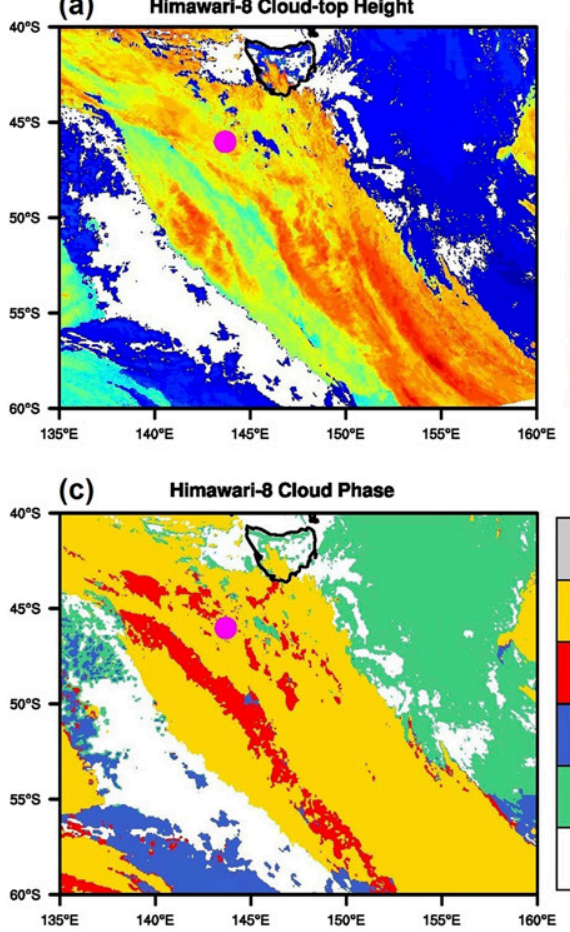

(b) Himawari-8 Cloud-top Temperature

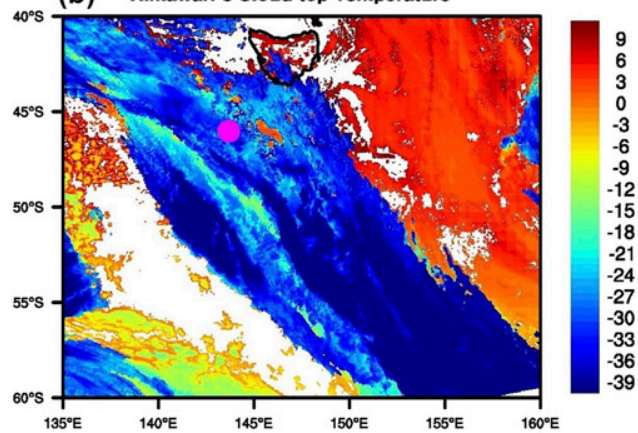

(d) Himawari-8 Cloud Type

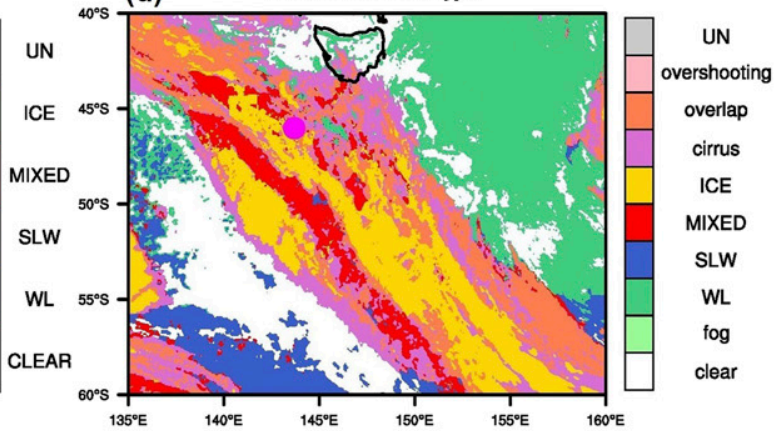

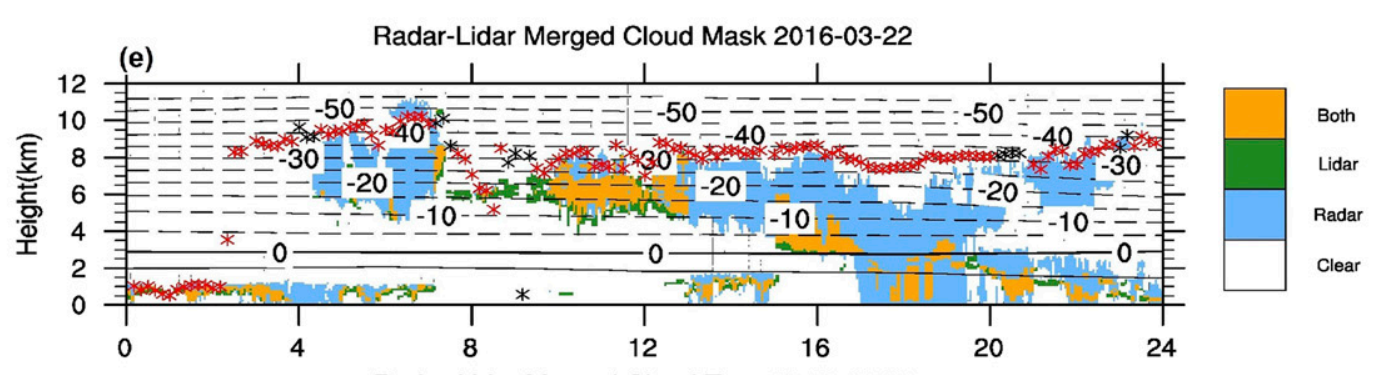

Radar-Lidar Merged Cloud Type 2016-03-22
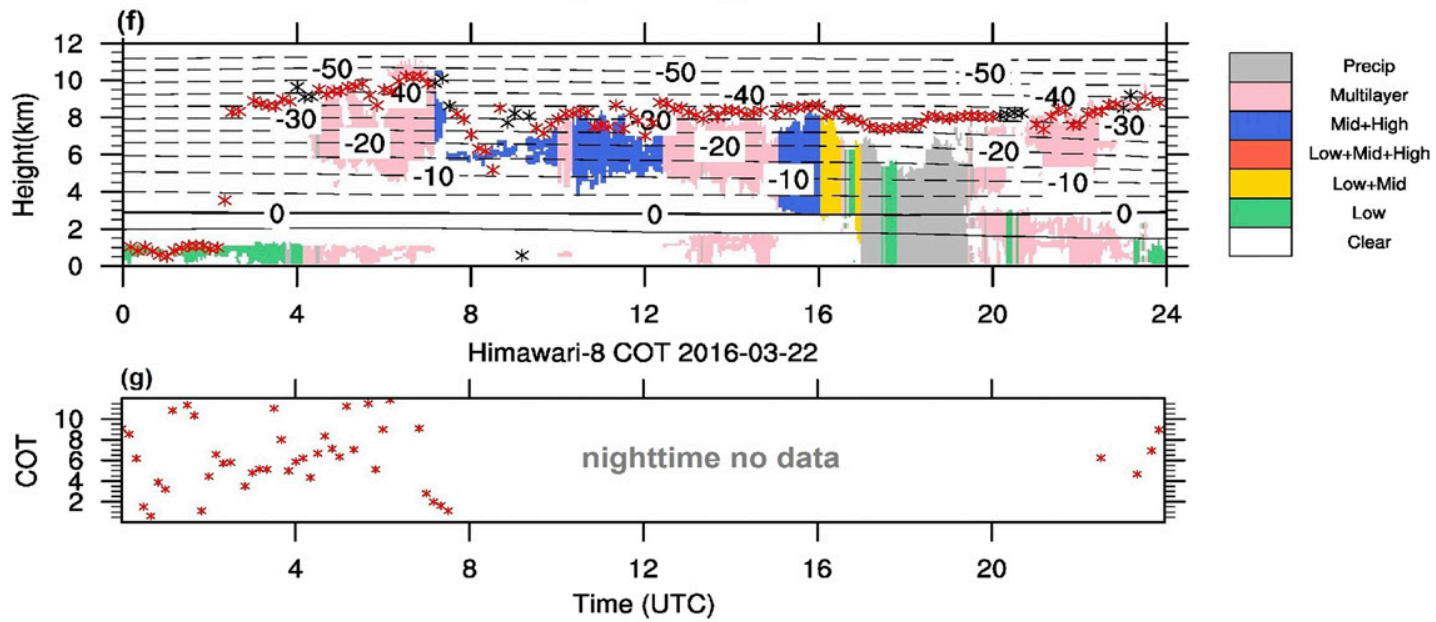

FIG. 1. An example of Himawari-8 cloud property retrievals with shipborne radar-lidar retrieved cloud properties for 22 Mar 2016 during CAPRICORN. (a) Himawari-8 cloud-top height at 1200 UTC 22 Mar 2016; (b) as in (a), but for cloud-top temperature; (c) as in (a), but for cloud phase; (d) as in (a), but for cloud type; (e) 24-h time series of shipborne radar-lidar vertical cloud mask overlaid with ERA-Interim temperature and collocated Himawari-8 cloud top heights shown by the asterisks; (f) as in (e) but for cloud cover type; and (g) 24-h time series of collocated Himawari-8 cloud optical depth. The magenta dots in (a)-(d) indicate the ship location at the time of the observations. Black asterisks in (e) and (f) indicate the collocated Himawari-8 cloud-top heights that are filtered out by the criteria. 
optically thin clouds or cloud layers, such as cirrus clouds.

\section{b. The CAPRICORN dataset}

The CAPRICORN-2016 experiment was conducted over the SO from 14 March to 15 April 2016. The ship traversed a large area of the $\mathrm{SO}$, making observations between $140^{\circ}$ and $152^{\circ} \mathrm{E}$ and between $42^{\circ}$ and $53^{\circ} \mathrm{S}$. During the 31-day cruise, a wide variety of meteorological conditions were met, including 10 cold or warm fronts and extratropical cyclones.

Detailed information and instrumentation deployed for the ship experiment is available in Mace and Protat (2018a,b). The shipborne cloud radar is a $95-\mathrm{GHz}$ lowcost Frequency Modulation-Continuous Wave Doppler cloud radar (Delanoë et al. 2016), which was operated at a temporal resolution of $12 \mathrm{~s}$ and four vertical resolutions $(12.5,25,100$, and $200 \mathrm{~m})$. The maximum altitude of the observation was $12 \mathrm{~km}$ and the minimum detectable radar reflectivity factor (dBZe) was $\sim-55 \mathrm{dBZ}$ e at $1 \mathrm{~km}$ (Delanoë et al. 2016). The lidar is a cloud-aerosol Leosphere RMAN-511 miniRaman lidar operating at $355 \mathrm{~nm}$, which has a vertical resolution of $15 \mathrm{~m}$ and temporal resolution of $35 \mathrm{~s}$ (Royer et al. 2014). A radar-lidar merged product is also produced where spatiotemporal averaged hydrometeor features detected by the radar and lidar are combined in a common grid. This merged product outputs the retrievals at 480 vertical layers with a vertical resolution of $25 \mathrm{~m}$. The minimum and maximum heights are $50 \mathrm{~m}$ and $12 \mathrm{~km}$, respectively, and the time resolution is $1 \mathrm{~min}$. To optimize cloud detection, any pixel in which a hydrometeor feature is detected by either of the instruments is recognized to be a cloudy pixel. At least two consecutive cloudy pixels are required to define a cloud layer, and a gap of at least $200 \mathrm{~m}$ is required to identify distinct layers. A cloud cover type (an example is shown in Fig. 1f) has been assigned to each profile from CAPRICORN using the lidar-radar merged cloud mask, Doppler velocity from the cloud radar, ship disdrometer precipitation, and ERA-Interim (Dee et al. 2011) temperature profiles interpolated to the cloud mask resolution. The first step is to detect the cloud tops and cloud bases for each layer of the cloud profile using the cloud mask. The heights of the $0^{\circ},-20^{\circ}$, and $-38^{\circ} \mathrm{C}$ isotherms $\left(\mathrm{H} 0^{\circ} \mathrm{C}, \mathrm{H}-20^{\circ} \mathrm{C}\right.$, and $\mathrm{H}-38^{\circ} \mathrm{C}$, respectively) are determined using the ERAInterim temperature profiles. Six cloud cover types are defined: (i) Precipitation, (ii) Low, (iii) Low + Mid, (iv) Low +Mid+High, (v) Mid+High, and (vi) Multilayer. The following rules are used for each type of cloud cover:
1) If the Doppler velocity averaged between the first cloud radar range bin and $\mathrm{H} 0^{\circ} \mathrm{C}$ is lower than $-2.5 \mathrm{~m} \mathrm{~s}^{-1}$, or if precipitation is detected by the disdrometer, the profile is classified as "Precipitation"; this classification supersedes the others.

2) If the profile is not a Precipitation profile and only has a single cloud layer, it is classified as

- "Low" if the cloud base is below $\mathrm{H} 0^{\circ} \mathrm{C}$ and the cloud top is below $\mathrm{H}-20^{\circ} \mathrm{C}$,

- "Low+Mid" if the cloud base is below $\mathrm{H} 0^{\circ} \mathrm{C}$ and the cloud top is between $\mathrm{H}-20^{\circ} \mathrm{C}$ and $\mathrm{H}-38^{\circ} \mathrm{C}$,

- "Low + Mid+High" if the cloud base is below $\mathrm{H} 0^{\circ} \mathrm{C}$ and the cloud top is above $\mathrm{H}-38^{\circ} \mathrm{C}$, or

- "Mid+High" if the cloud base is above $\mathrm{H} 0^{\circ} \mathrm{C}$ (note that this category includes profiles with high clouds only).

3) If the profile is not a Precipitation profile and has more than one cloud layer, it is classified as

- "Low" if the lowest cloud base is below $\mathrm{H} 0^{\circ} \mathrm{C}$ and the highest cloud top is below $\mathrm{H}-20^{\circ} \mathrm{C}$, or

- "Mid+High" if the lowest cloud base is above $\mathrm{H} 0^{\circ} \mathrm{C}$ (note that this category includes rare occasions of profiles with multiple high cloud layers).

4) "Multilayer" for all other multilayer situations. The largest contributor in this category over the Southern Ocean is when there is a low cloud layerand a detached midtropospheric or upper-tropospheric cloud layer. These situations were identified as very challenging in terms of cloud-radiation interactions in models (Protat et al. 2017).

In this study, the CTH is defined as the altitude of the highest pixel that is characterized as cloud in the merged radar-lidar mask. Accordingly, the interpolated ERAInterim temperature at that cloud top is considered as the ship-based estimate of CTT.

\section{c. CALIPSO cloud products}

CALIPSO (Winker et al. 2006) carries CALIOP, a nadir-viewing two-wavelength (532 and $1064 \mathrm{~nm}$ ) polarization-sensitive lidar (Liu et al. 2009). CTH is observed by CALIOP with a vertical resolution of between $30 \mathrm{~m}$ (between the surface and $8.2 \mathrm{~km}$ ) and $60 \mathrm{~m}$ (from 8.2 to $20.2 \mathrm{~km}$ ). The CALIOP dataset used in this study is the level-2, 1-km cloud layer, validated stage 1 version 3 product. Due to the high sensitivity of the lidar to optically thin clouds, CALIOP is capable of detecting cloud layers with an optical thickness of 0.01 (McGill et al. 2007; Vaughan et al. 2009), hence it is able to provide accurate estimates of the physical boundary of $\mathrm{CTH}$, even for subvisible clouds. Once the CTH is determined, CTT is estimated using the Goddard Earth Observing System Model version 5 (GEOS-5) 
product provided to the CALIPSO project by the Global Modeling and Assimilation Office Data Assimilation System (Rienecker et al. 2008). The GEOS-5 model only has a $0.625^{\circ}$ longitude $\times 0.5^{\circ}$ latitude grid resolution, and 42 vertical levels, which are much coarser than the spatial resolution of CALIOP itself. As such, the conversion from CTH to CTT may introduce potential uncertainties in the CALIOP CTT estimates.

One year (2016) of CALIOP observations over a large domain of the south Indian Ocean and South Pacific Ocean $\left(43^{\circ}-60^{\circ} \mathrm{S}, 135^{\circ}-160^{\circ} \mathrm{E}\right)$ are employed for comparison with the Himawari-8 products. This domainrather than an extensive SO sector-was chosen because the selected region covers the area sampled by the CAPRICORN experiment, hence representing the typical meteorology and cloud regimes within this region. The 1-yr CALIOP data collected over this region also provide sufficient samples to allow for a better appreciation of the representativeness of the 31-day CAPRICORN observations, which now start to be used for characterizing the nature of the SO clouds (e.g., Mace and Protat 2018a,b).

\section{Data collocation, averaging, and filtering}

\section{a. Data collocation for Himawari-8 and CAPRICORN observations}

Given that the shipborne and Himawari-8 observations have different spatiotemporal resolutions, appropriate averaging is needed to account for sampling differences between the two datasets. In addition, being known as the "Roaring Forties," the strong westerly winds of the SO storm track can lead to the fast propagation of the cloud systems eastward, thus any "downwind effect" needs be properly accounted for. To minimize the errors caused by these issues, a number of spatiotemporal averaging methods have been recommended in the literature, involving the use of various space-time windows that depend on the nature of the satellites and products used and the meteorology over the studied regions (e.g., Roebeling et al. 2008; Wolters et al. 2008; Protat et al. 2017). Following the literature, a space-time averaging method is also used in this study, with the assumption that the space-time conversion is sufficient to represent the cloud properties from the corresponding satellite pixel(s).

To take advantage of the high spatiotemporal resolution of Himawari-8 and to minimize the effects of broken cloud fields or mismatch in cloud detection between the satellite and ship-based observations, collocation is performed by taking the satellite data from $9(3 \times 3)$ pixels nearest to the averaged ship location, corresponding to a square sample area of $\sim 36 \mathrm{~km}^{2}$ $(6 \mathrm{~km} \times 6 \mathrm{~km})$. The 10 -m airflow during the cruise was dominated by westerlies with an average wind speed of $\sim 10 \mathrm{~m} \mathrm{~s}^{-1}$, which corresponds to a distance (period) of $\sim 6 \mathrm{~km}(10 \mathrm{~min})$. Thus, a 10-min track length of the westerly flow is comparable to the length of the nominated satellite sample area. Based upon this, we averaged the ship observations over a 10-min temporal collocation window. In so doing, the downwind effect is implicitly accounted for. To test the sensitivity of the results to the space-time window size, a few other collocation criteria have also been examined, including changing the number of collocated pixels (i.e., Himawari-8 sample area) to $1(1 \times 1)$ and $25(5 \times 5)$. It is found that the results with the alternative sampling areas (not shown) are qualitatively similar to that from the chosen sampling area. The multipixel criteria also produce robust statistics with a desirable sample size. If only one single nearest pixel is used, the sample size for the matched Himawari-8 CTH is reduced by $43.8 \%$ due to a large number of clear or partly cloudy pixels being retrieved. This becomes problematic when cloud optical properties are examined, which are only available for daytime observations in the current products.

We note that a parallax correction is currently not performed on the operational version of the Himawari-8 cloud products disseminated by the BoM. An attempt to assess the impact of any potential parallax bias on the error statistics is made in section 5, along with discussions on implications.

\section{b. Data collocation for Himawari-8 and CALIPSO observations}

Compared to the space-time collocation between the shipborne and Himawari- 8 observations, the collocation between Himawari-8 and CALIOP datasets is relatively more straightforward. Given their comparable spatial resolutions, the coincident observations are identified simply by searching for the nearest Himawari-8 pixel for each CALIOP data point along the CALIOP ground track with a maximum time difference of 5 min. Like other passive sensors, AHI's detection efficiency is expected to decrease at low optical thickness. Some previous studies on evaluating passive spaceborne sensors with CALIOP excluded clouds with small cloud optical thickness (COT) in the range of $0.1-1$ as retrieved by CALIOP (e.g., Stubenrauch et al. 2010; Benas et al. 2017; Kniffka et al. 2013; Taylor et al. 2017), while others have not (e.g., Reuter et al. 2009). This is due, in part, to the nature of different products produced at various resolutions, different time-space collocation criteria, and different application needs, although in theory, the detection limit for passive imagers is estimated to 
TABLE 1. CAPRICORN vs Himawari-8 CTH. Note that in the filtered results the percentages of individual cloud types do not sum up to $100 \%$ due to the removal of additional pixels as a result of individual filtering.

\begin{tabular}{|c|c|c|c|c|c|c|c|c|c|c|}
\hline & \multicolumn{5}{|c|}{ Nonfiltered } & \multicolumn{5}{|c|}{ Filtered } \\
\hline & Counts (\%) & $r$ & Bias & RMSE & $\sigma$ & Counts (\%) & $r$ & Bias & RMSE & $\sigma$ \\
\hline All & $3697(100 \%)$ & 0.751 & 0.257 & 2.118 & 4.486 & 3003 (100\%) & 0.837 & 0.226 & 1.684 & 2.835 \\
\hline All-Cirrus-Overlap & $2650(71.9 \%)$ & 0.826 & 0.127 & 1.575 & 2.482 & $2248(77.0 \%)$ & 0.912 & 0.006 & 1.095 & 1.200 \\
\hline WL & $997(27.8 \%)$ & 0.181 & -0.683 & 1.736 & 3.016 & $790(31.2 \%)$ & 0.111 & -0.324 & 1.050 & 1.103 \\
\hline SLW & $869(23.2 \%)$ & 0.426 & 0.056 & 1.252 & 1.570 & $721(25.4 \%)$ & 0.665 & 0.205 & 0.860 & 0.741 \\
\hline Mixed & $374(10.0 \%)$ & 0.745 & 0.204 & 1.569 & 2.469 & $215(9.7 \%)$ & 0.933 & 0.599 & 0.839 & 0.708 \\
\hline Ice & $410(10.9 \%)$ & 0.742 & 0.535 & 1.332 & 1.777 & $303(10.7 \%)$ & 0.833 & 0.302 & 0.898 & 0.809 \\
\hline Cirrus & $504(13.4 \%)$ & 0.349 & 0.847 & 2.803 & 7.872 & $249(10.3 \%)$ & 0.433 & 0.252 & 2.627 & 6.933 \\
\hline Overlap & $478(14.7 \%)$ & 0.077 & 1.913 & 2.694 & 7.274 & $252(10.9 \%)$ & -0.003 & 1.778 & 2.660 & 7.106 \\
\hline
\end{tabular}

be $0.1-0.3$ depending on the algorithm (Hamann et al. 2014). In our study, no filtering is applied to the COT when the broad statistics are calculated (we further note that COT is not available in the 1-km CALIOP product). We will revisit this issue when the comparison is performed as a function of Himawari-8 COT (section 5d), using daytime observations only.

\section{c. Filtering aspects}

Complicated cloud fields (e.g., large cloud inhomogeneity, multilayer clouds, and broken cloudiness) are common over the SO storm-track region (Mace et al. 2009). These cloud fields are characterized by high spatiotemporal variability and sharp physical boundaries, which make the evaluation difficult when the point measurements from the ship are compared against the spaceborne observations over an area (e.g., Illingworth et al. 2007; Bouniol et al. 2010). To minimize the sampling biases caused by the nature of the cloud field, a further step is undertaken where some filtering is performed prior to the analysis. By doing so, it is expected that only cloud fields with relatively high homogeneity (except for subpixel heterogeneity) are used for the comparison so that only systematic differences (if any) between the datasets will stand out. These filtering criteria include the following:

1) A 40-min moving window is run through the shipborne 10-min average CTH time series to remove cloud edges from the analysis. If a sharp step change is present, which is determined by the maximum difference between the center data point and the two consecutive points on either side of the center data point exceeding $2 \mathrm{~km}$, the center data point is then considered to be too close to cloud edges and is not used for further analysis. The same rule is also applied to the CTT time series except that $12^{\circ} \mathrm{C}$ is used as the threshold value. Additional analysis has also been performed to test the sensitivity of the results to the size of the moving window (e.g., $60 \mathrm{~min}$ with seven data points) and the threshold values (e.g., $4 \mathrm{~km}$ for $\mathrm{CTH}$ and $18^{\circ} \mathrm{C}$ for CTT). The findings are qualitatively similar and do not change the overall conclusions of this study.

2) A cloud type consistency check is required for the collocated nine pixels of the Himawari-8 field. If the maximum number of pixels of the same "cloud type" is less than five (i.e., an area fraction of the same cloud type is less than $55 \%$ ), then the observed cloud field is considered to be highly inhomogeneous and the corresponding average CTH/CTT value is not used for further analysis. As a further check, statistics have been performed with and without this criterion. Results suggest that using the homogeneity constraint is necessary for mitigating the impact resulting from the complexity of the observed cloud field (i.e., nonsystematic biases). Note, however, that uncertainties introduced by surface contamination that originates from any clear sky pixels within the ninepixel area cannot be completely ruled out.

3) For the 10-min average CTH/CTT time series, if either of the datasets records clear sky or missing values, then the paired data point is also discarded for further analysis.

After the filtering, the total valid (not clear or missing) sample size is reduced by $\sim 19 \%$ (Tables 1 and 2). The performance of the Himawari-8 CTH and CTT retrievals is more stable than the nonfiltered results, as measured by various statistics in Tables 1 and 2. Therefore, the rest of this paper will focus on the analysis using the filtered data only, noting, however, that results from the nonfiltered data are qualitatively similar.

\section{Results}

An example showing a 24-h time series of the cloudmask and cloud cover type from the shipborne radarlidar merged product and the collocated Himawari-8 CTHs are shown in Figs. 1e and 1f. This example 
TABLE 2. CAPRICORN vs Himawari-8 CTT.

\begin{tabular}{|c|c|c|c|c|c|c|c|c|c|c|}
\hline & \multicolumn{5}{|c|}{ Nonfiltered } & \multicolumn{5}{|c|}{ Filtered } \\
\hline & Counts (\%) & $r$ & Bias & RMSE & $\sigma$ & Counts (\%) & $r$ & Bias & RMSE & $\sigma$ \\
\hline All & $3697(100 \%)$ & 0.731 & -2.472 & 12.616 & 159.211 & $2974(100 \%)$ & 0.820 & -2.526 & 10.069 & 101.413 \\
\hline All-Cirrus-Overlap & $2650(71.9 \%)$ & 0.816 & -0.718 & 9.497 & 90.230 & $2249(77.2 \%)$ & 0.903 & -1.611 & 6.544 & 42.845 \\
\hline WL & $997(27.8 \%)$ & 0.200 & 3.294 & 10.601 & 112.502 & $789(30.9 \%)$ & 0.171 & 1.029 & 6.301 & 39.751 \\
\hline SLW & $869(23.2 \%)$ & 0.506 & -3.402 & 6.522 & 42.582 & $735(25.9 \%)$ & 0.802 & -4.446 & 3.351 & 11.247 \\
\hline Mixed & $374(10.0 \%)$ & 0.642 & -2.120 & 9.039 & 81.921 & $225(10.1 \%)$ & 0.834 & -4.209 & 5.311 & 28.332 \\
\hline Ice & $410(10.9 \%)$ & 0.361 & -3.504 & 9.002 & 81.230 & $289(10.3 \%)$ & 0.507 & -1.650 & 6.266 & 39.396 \\
\hline Cirrus & $504(13.4 \%)$ & 0.201 & -4.017 & 17.075 & 292.129 & $238(10.6 \%)$ & 0.212 & -1.092 & 16.723 & 280.84 \\
\hline Overlap & $478(14.7 \%)$ & 0.116 & -11.295 & 16.595 & 275.973 & $253(10.5 \%)$ & 0.142 & -11.173 & 16.466 & 272.29 \\
\hline
\end{tabular}

captures a variety of clouds including a passage of a frontal cloud band that can be seen in the Himawari-8 CTH (Fig. 1a) and CTT (Fig. 1b) images as well as the cloud-top thermodynamic phase (Fig. 1c) and cloud type (Fig. 1d) at 1200 UTC 22 March. Prior to the frontal passage, the observations recorded an extensive field of high-level clouds (ice and/or mixed phase) occasionally lying over some warm boundary layer clouds. Overall, the collocated Himawari-8 CTHs are in a good agreement with the CTHs determined by the shipborne cloudmask profiles (Fig. 1e), especially on some of the uniform boundary layer clouds (0000-0200 UTC) and nonfrontal clouds with moderate geometric thickness. Discrepancies are noted for the frontal precipitating clouds (around 1700-2000 UTC), where the Himawari-8 CTHs are 1$2 \mathrm{~km}$ higher than the shipborne counterparts. Given the good agreement in the surrounding areas, these discrepancies may largely be attributed to the strong attenuation of the radar signals through heavy precipitation and the full attenuation of the lidar signal through low-level liquid clouds, resulting in a low bias in the shipborne CTHs estimates. Large discrepancies are also noted in the vicinity of the prefrontal high cloud anvil that was observed by Himawari-8 but not the shipborne measurements (around 0200-0400 UTC). The Himawari-8 cloud type retrievals also suggest an overlapping scenario for these clouds (not shown), which is not identified by the shipborne sensors. Unlike the frontal cloud scene, only shallow low clouds are detected by the ship in this instance. Given that similar shallow low clouds with overlying clouds are also observed by the ship around $0400-0600$, it is unlikely that the lack of overlying clouds around $0200-0400$ UTC is due to the limitation of the shipborne active sensors (i.e., lidar extinction and radar attenuation). Another discrepancy is noted in the period 0600-0700 UTC, where the radar-only CTHs are much higher than the Himawari- 8 counterpart. Last, some discrepancy is noticed for some thin layers of supercooled liquid water clouds that were only picked up by the lidar (around 0800-0900 UTC). Instead, the
Himawari-8 cloud type indicates cirrus clouds and features a high bias in CTHs.

\section{a. Evaluation of all clouds}

Figure 2a shows the scatterplots of the frequency distribution of CTHs derived from the shipborne and Himawari-8 datasets. The diagram also reveals the general statistics of the CTHs sampled during the cruise. Overall, the results suggest a good consistency between the radar-lidar and Himawari-8 CTHs, with a correlation coefficient of 0.837 , a mean bias error of $0.226 \mathrm{~km}$, and a root-mean-square error (RMSE) of $1.684 \mathrm{~km}$ (Table 1). According to the ship observations, low clouds with CTHs less than $3 \mathrm{~km}$ dominate the statistics, presenting $65 \%$ of the time. Mid-top clouds with CTHs in the range of 3-6 km are less frequent (14\%), whereas high-top clouds (CTHs $>6 \mathrm{~km}$ ) were observed $21 \%$ of the time. Despite the overall good agreement, Himawari-8 observed a fraction of mid- to high-top clouds $(\sim 9 \%)$ that are categorized as low clouds by the ship measurements. Also, there appears to be a lack of CTHs at $\sim 3 \mathrm{~km}$ in the Himawari-8 product.

Figure $2 \mathrm{c}$ shows the scatterplots for $\mathrm{CTHs}$ derived from the CALIOP and Himawari-8 datasets. Despite the wider spread of the frequency distributions, the 1-yr CALIOP-Himawari-8 comparison shows that low-top clouds $(\mathrm{CTHs}<3 \mathrm{~km})$ dominate the climatology $(\sim 42 \%)$, qualitatively similar to Fig. 2a. Mid-top clouds between 3 and $6 \mathrm{~km}$ become more common, presenting $\sim 20 \%$ of the time, whereas high-top clouds (CTHs $>6 \mathrm{~km}$ ) were observed $\sim 38 \%$ of the time. The difference between these statistics suggests that CAPRICORN may have under sampled the mid- and high-top clouds compared to the CALIOP observations over a longer period and a more extended geographical region of the SO. Another possibility is the sensitivity issue between two viewing geometries. Once again, the lack of CTHs at $\sim 3 \mathrm{~km}$ in the Himawari-8 product, as noted in Fig. 2a, is present in the comparison with CALIOP, confirming the robustness of this error. Overall, there appears to be a 

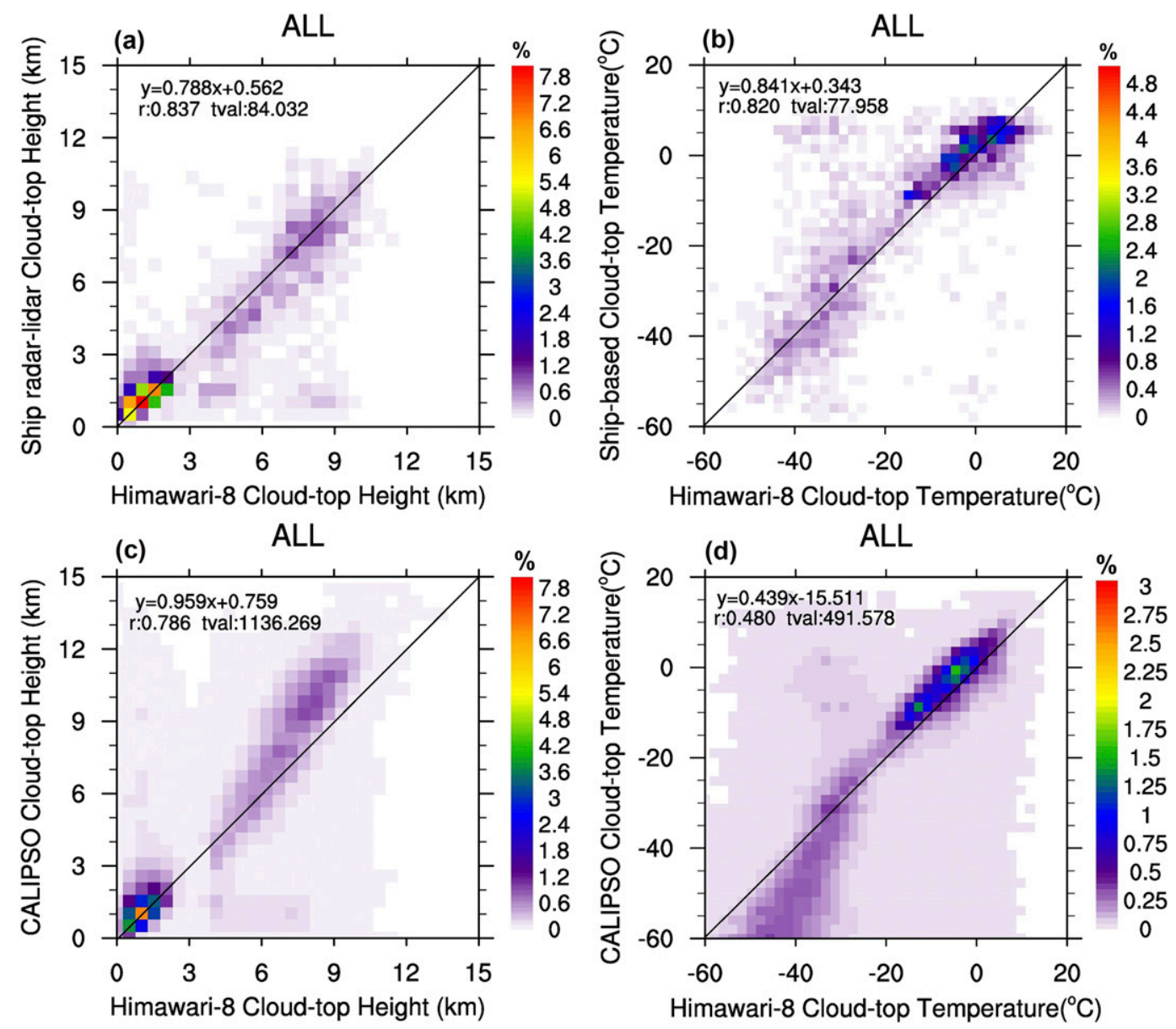

FIG. 2. Frequency density plots for Himawari-8 CTHs and CTTs evaluated using the shipborne and CALIOP retrievals. (a) Himawari-8 CTHs vs shipborne CTHs; (b) Himawari-8 CTTs vs shipborne CTTs; (c) Himawari-8 CTHs vs CALIOP CTHs; and (d) Himawari-8 CTTs vs CALIOP CTTs. All collocated cloud samples are considered in the comparisons. The densities sum to $100 \%$ for each plot.

mean low bias of $-0.570 \mathrm{~km}$ (Table 3 , most obvious for CTH $>6 \mathrm{~km}$ ), meaning that the Himawari-8 CTHs are on average falling between the physical CTHs observed by CALIOP and the shipborne radar-lidar estimates (Table 1), which is somewhat expected from the high cloud detection issues from the ship in multilayer situations.

The same analysis is also performed for CTTs, as shown in Figs. $2 \mathrm{~b}$ and $2 \mathrm{~d}$ for the comparisons with CAPRICORN and CALIOP, respectively. Once again, the CAPRICORN and Himawari-8 CTTs compare reasonably well, with a correlation coefficient of 0.820 , a mean bias error of $-2.526^{\circ} \mathrm{C}$, and an RMSE of $10.069^{\circ} \mathrm{C}$ (Table 2). Warm cloud tops $\left(\mathrm{CTT}>0{ }^{\circ} \mathrm{C}\right)$ account for $35 \%$ of the total samples whereas $30 \%$ of the CTTs fall in the range of $-10^{\circ}-0^{\circ} \mathrm{C}$. The CTTs of the $9 \%$ misallocated low clouds identified in Fig. 2a are generally warmer than $-20^{\circ} \mathrm{C}$ according to the ship measurements but colder than $-20^{\circ} \mathrm{C}$ according to Himawari-8. Interestingly, however, the lack of CTH at $\sim 3 \mathrm{~km}$ as seen in Fig. $2 \mathrm{a}$ does not have a corresponding gap in the CTT statistics. The CALIOP-Himawari-8 CTT comparison (Fig. 2d), on the other hand, shows some unique characteristics. Despite the total mean bias of $1.343^{\circ} \mathrm{C}$ (Table 4), a slight cold bias is found for the majority of warmer clouds $\left(-30^{\circ} \mathrm{C}<\mathrm{CTT}<0^{\circ} \mathrm{C}\right)$ whereas a warm bias is evident for the colder clouds $\left(\mathrm{CTT}<-30^{\circ} \mathrm{C}\right)$. Overall, the Himawari-8

TABLE 3. CALIOP vs Himawari-8 CTH.

\begin{tabular}{lccccc}
\hline & Counts $(\%)$ & $r$ & Bias & RMSE & $\sigma$ \\
\hline All & 800528(100\%) & 0.786 & -0.570 & 2.297 & 5.274 \\
All-Cirrus- & $497355(62.1 \%)$ & 0.822 & -0.737 & 1.992 & 3.970 \\
$\quad$ Overlap & & & & & \\
WL & $76739(9.6 \%)$ & 0.106 & -0.992 & 2.102 & 4.421 \\
SLW & $195645(24.8 \%)$ & 0.346 & -0.595 & 1.831 & 3.354 \\
Mixed & $107955(13.5 \%)$ & 0.515 & -0.793 & 2.394 & 5.729 \\
Ice & $117016(14.6 \%)$ & 0.685 & -0.754 & 1.732 & 2.999 \\
Cirrus & $148936(18.6 \%)$ & 0.519 & -0.001 & 2.782 & 7.741 \\
Overlap & $153509(19.2 \%)$ & 0.502 & -0.578 & 2.588 & 6.699 \\
\hline
\end{tabular}


product places too much cloud around $-40^{\circ} \mathrm{C}$. The lack of CTHs at $\sim 3 \mathrm{~km}$ in the Himawari- 8 product, once again, does not seem to correspond to any gap in the CTT comparison with CALIOP.

\section{b. Evaluation of individual cloud types}

To better understand the origin of the identified biases, we also evaluate the CTH grouped by cloud type, as defined by the Heidinger classification (Heidinger 2011) applied to Himawari-8. Looking first at the CAPRICORN-Himawari- 8 comparisons, the results for CTH (Fig. 3 and Table 1) show that strong correlations are found for MIXED and ICE cloud types $(r>0.8)$ and, to a lesser extent, SLW $(r>0.6)$, whereas the correlations for WL and CIRRUS are relatively poor ( $r \sim 0.1$ and 0.4, respectively). The absence of CTHs at $\sim 3 \mathrm{~km}$, as discussed in section $4 \mathrm{a}$, is most evident in the SLW and MIXED types. No ICE is diagnosed below $3 \mathrm{~km}$. The CIRRUS and OVERLAP cloud types feature the largest mean biases and RMSEs (almost no correlation is found for the OVERLAP type). An interesting feature noted for these two cloud types is that the Himawari-8 CTHs reach saturation around $10 \mathrm{~km}$, while the ship-based CTHs commonly extend to $12 \mathrm{~km}$. Also, Himawari-8 diagnoses some CIRRUS type around $2 \mathrm{~km}$, which is not possible at this latitude range for that time of year. No explanation can readily be found for this discrepancy. Nevertheless, if the CIRRUS and OVERLAP types are not included in the statistics, the two CTH datasets are much more consistent, with an $r$ of 0.912 , a mean bias of $0.006 \mathrm{~km}$, and an RMSE of $1.095 \mathrm{~km}$. The linear regression is also much closer to the one-to-one line.

The overall characteristics of the CTT comparisons (Fig. 4 and Table 2) are comparable to that of the CTHs (Fig. 3). Despite the mean cold bias in the Himawari-8 CTTs when all clouds are considered, the warm bias in Himawari-8 WL type (Fig. 4a) corresponds well to the low bias in the WL CTHs (Fig. 3a). Interestingly, however, the CTT bias distribution for SLW clouds (Fig. 4b) is not as scattered as the corresponding CTH bias, although a cold bias is evident. Also, no gaps are identified in the CTTs for SLW and MIXED types that correspond to the absence of CTHs at $\sim 3 \mathrm{~km}$ (Figs. $3 \mathrm{~b}, \mathrm{c})$, while ICE is only diagnosed below $\sim-20^{\circ} \mathrm{C}$. Given that the Himawari-8 CTT retrievals are not directly affected by potential errors in the NWP inputs, they are expected to be more accurate than the $\mathrm{CTH}$ retrievals. That said, the ship-based CTT estimates are derived from the interpolated ERA-Interim reanalysis data (not direct measurements), making an error estimate for the ship-based CTTs more difficult. This may introduce another source of biases. Once again, a
TABLE 4. CALIOP vs Himawari-8 CTT.

\begin{tabular}{lccrcc}
\hline \hline & Counts $(\%)$ & $r$ & Bias & RMSE & $\sigma$ \\
\hline All & $805457(100 \%)$ & 0.480 & 1.343 & 25.176 & 634.536 \\
All-Cirrus- & $499573(62.0 \%)$ & 0.571 & 1.542 & 21.588 & 466.356 \\
$\quad$ & & & & & \\
Overlap & & & & & \\
SLW & $1720(9.6 \%)$ & 0.040 & 0.828 & 32.958 & 1086.41 \\
Mixed & $108315(13.4 \%)$ & 0.151 & -1.186 & 19.642 & 385.891 \\
Ice & $117102(14.5 \%)$ & 0.210 & 2.631 & 21.008 & 441.357 \\
Cirrus & $149582(18.6 \%)$ & 0.147 & 0.586 & 13.516 & 182.675 \\
Overlap & $154043(19.1 \%)$ & 0.197 & 4.329 & 22.471 & 598.865 \\
\hline
\end{tabular}

saturation issue is noted in Himawari-8 CTTs for CIRRUS and OVERLAP types (Figs. 4e,f), which corresponds to the CTHs saturated around $10 \mathrm{~km}$ (Figs. 3e,f): the Himawari- 8 CTTs mostly reside in the range from $-25^{\circ}$ to $-50^{\circ} \mathrm{C}$ for these two cloud types whereas the ship-based CTTs span from $10^{\circ}$ to $-60^{\circ} \mathrm{C}$. If the CIRRUS and OVERLAP types are not included in the comparisons, the two CTT datasets compare better, with an $r$ of 0.903 , a mean bias of $-1.611^{\circ} \mathrm{C}$, and an RMSE of $6.544^{\circ} \mathrm{C}$.

Turning to the CTH and CTT comparisons with CALIOP for the individual cloud types (Figs. 5 and 6 , Tables 3 and 4), WL shows the lowest correlation coefficients $(r<0.11)$, with a low (warm) bias of $0.992 \mathrm{~km}$ $\left(0.828^{\circ} \mathrm{C}\right)$, consistent with that from the CAPRICORNHimawari-8 comparisons. Despite the similar pattern compared to Figs. 3 and 4, a notable feature is that there is always a fraction of higher (colder) cloud tops that is detected by CALIOP but missed by Himawari-8. This is very likely a result of the higher sensitivity of CALIOP in detecting optically thin clouds at higher altitudes (colder temperatures). The lack of CTHs at $\sim 3 \mathrm{~km}$, once again, is most pronounced in the SLW and MIXED CTH comparisons, with no corresponding gaps in the CTT comparisons. ICE is only diagnosed above $\sim 3 \mathrm{~km}$ (colder than $\sim-20^{\circ} \mathrm{C}$ ). The lack of ICE at lower CTHs (warmer CTTs) may be an artifact resulting from the operational decision made on the $\beta$ thresholds in favor of the diagnostics of SLW or MIXED types at relatively cold CTTs, as suggested by other observational evidence (Pavolonis 2010, and references therein), coupled with the longstanding biases in the boundary layer height and inversion. Another noted feature is that the MIXED cloud type (Figs. 5c and 6c), which was primarily detected in the altitudes of 4-9 km during CAPRICORN ( $\sim 50 \%$ relative frequency), has a tendency toward lower altitudes $(\sim 55 \%$ within the lowest $3 \mathrm{~km})$ in the CALIOPHimawari-8 comparison. This discrepancy is also evident in the CTT scatterplot (Fig. 6c versus Fig. 4c), suggesting that the MIXED cloud type in the lower altitudes (warmer temperatures) might be undersampled during CAPRICORN due, possibly, to geographical and/or 

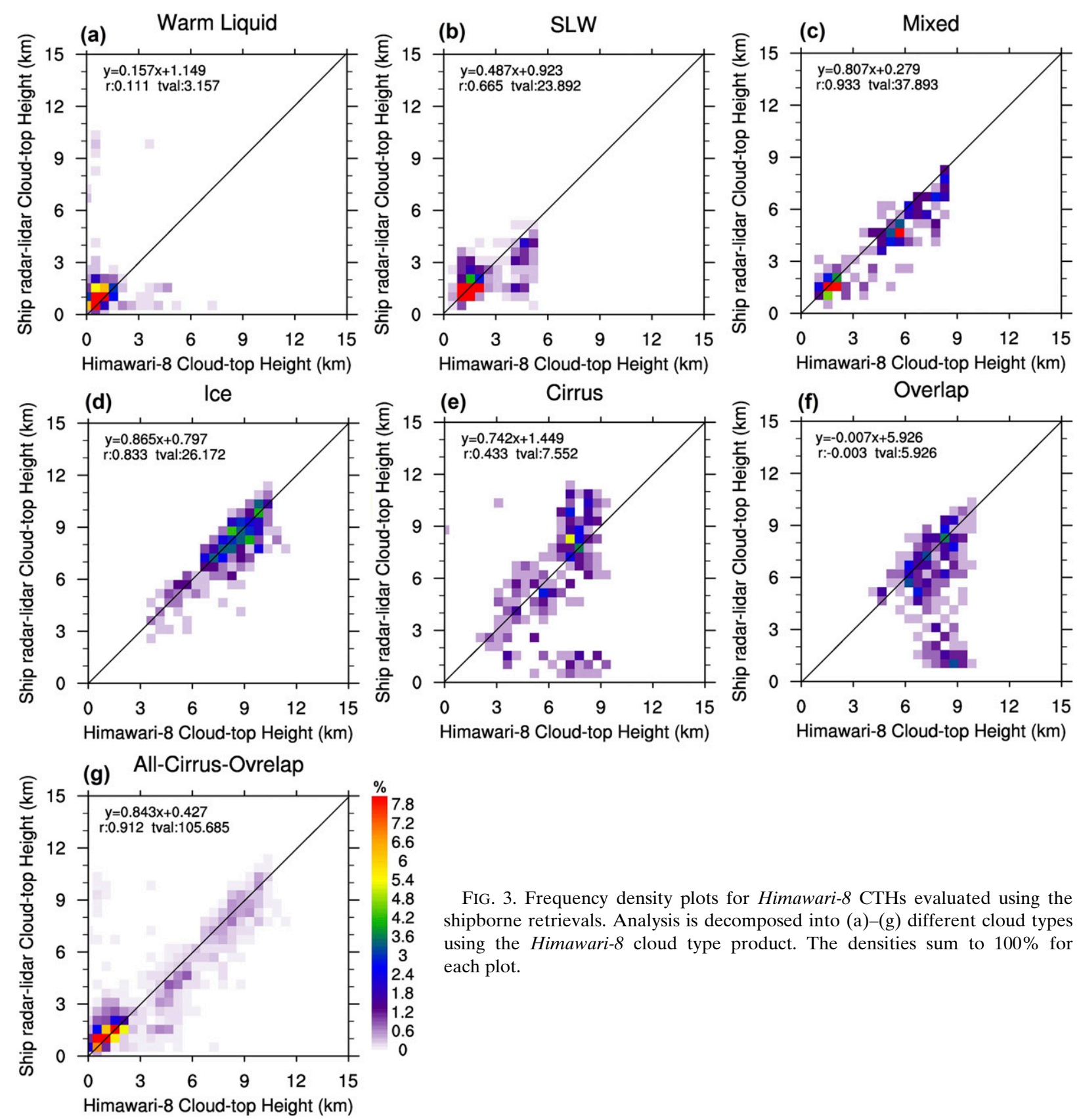

FIG. 3. Frequency density plots for Himawari-8 CTHs evaluated using the shipborne retrievals. Analysis is decomposed into (a)-(g) different cloud types using the Himawari-8 cloud type product. The densities sum to $100 \%$ for each plot.

seasonal sampling biases. Using A-Train observations, Huang et al. (2012b, 2016) show that SLW and MIXED cloud tops are more frequently observed over the higher latitudes of the SO. The CTHs and CTTs of the CIRRUS and OVERLAP types, once again, compare poorly with the CALIOP counterparts. The saturation issue is evident for Himawari-8 with CTTs primarily residing in the range from $-25^{\circ}$ to $-50^{\circ} \mathrm{C}$, whereas the CALIOP CTTs spread from $10^{\circ}$ to $-60^{\circ} \mathrm{C}$ for these two cloud types. More interestingly, there appears to be a fraction of cloud being identified by
CALIOP with CTH (CTT) less than $2 \mathrm{~km}$ (greater than $-10^{\circ} \mathrm{C}$ ). This discrepancy, once again, is consistent with the comparison with the limited shipbased estimates (Figs. 3e,f and 4e,f). Compared to Himawari-8, it is less likely for CALIOP to miss the optically thin clouds at higher altitudes. As such, it is likely that this fraction of the CIRRUS and OVERLAP types are a misclassification by the ACHA algorithm. Pavolonis and Heidinger (2004) reported that this algorithm is slightly more prone to false cloud overlap detection. 

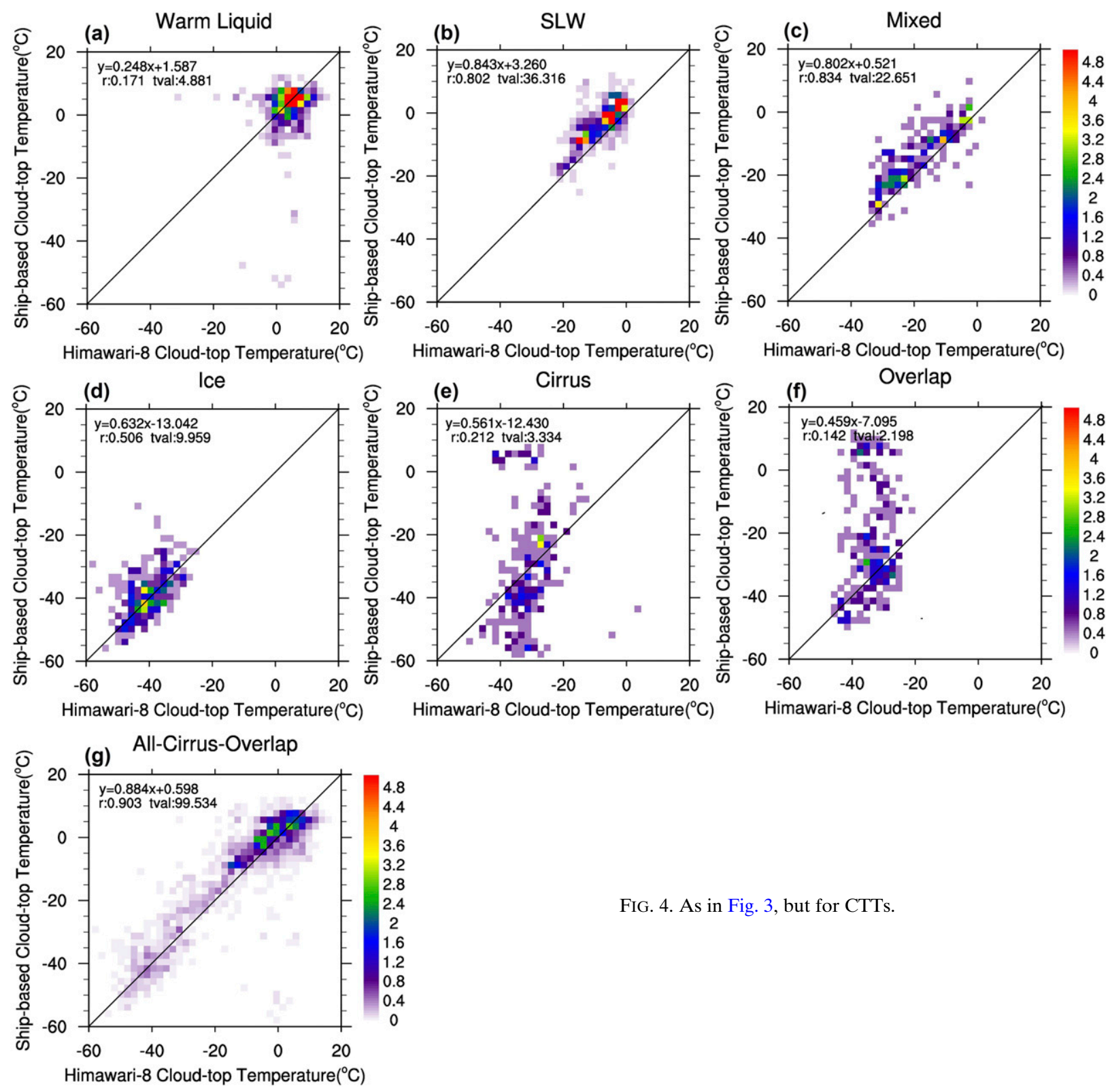

FIG. 4. As in Fig. 3, but for CTTs.

To put this scenario into perspective, a typical example is shown in Fig. 7, where collocated CTHs derived from a CALIPSO-CloudSat merged product (DARDAR-MASK; Delanoë and Hogan 2010), a CloudSat-only cloud classification product (Sassen and Wang 2008), and Himawari-8 are compared. In the areas of $51^{\circ}-51.5^{\circ} \mathrm{S}$ and $53.6^{\circ}-54^{\circ} \mathrm{S}$, some CIRRUS clouds are identified by Himawari- 8 with CTHs residing at $\sim 5-7$ and $4 \mathrm{~km}$, respectively. The corresponding CTHs retrieved by the merged product (most of which are only detected by CALIPSO), however, are primarily below 4 and $0.5 \mathrm{~km}$. These discrepancies, consistent with the presented climatology, suggest that these "CIRRUS clouds" diagnosed by the ACHA algorithm, are very likely a misclassification.

A more detailed characterization of the Himawari-8 CTH biases are shown in the probability density function (PDF) plots in Fig. 8. Overall, the CTH bias with respect to the ship-based measurements is constrained within $\pm 1 \mathrm{~km}$, although the bias distributions for various cloud types differ considerably. Most of the distributions are right-skewed (except for the MIXED type), with a larger spread and longer tail in the positive bias. On the other hand, the CTH bias distributions with respect to CALIOP feature a much longer tail in the negative bias for all cloud types, 

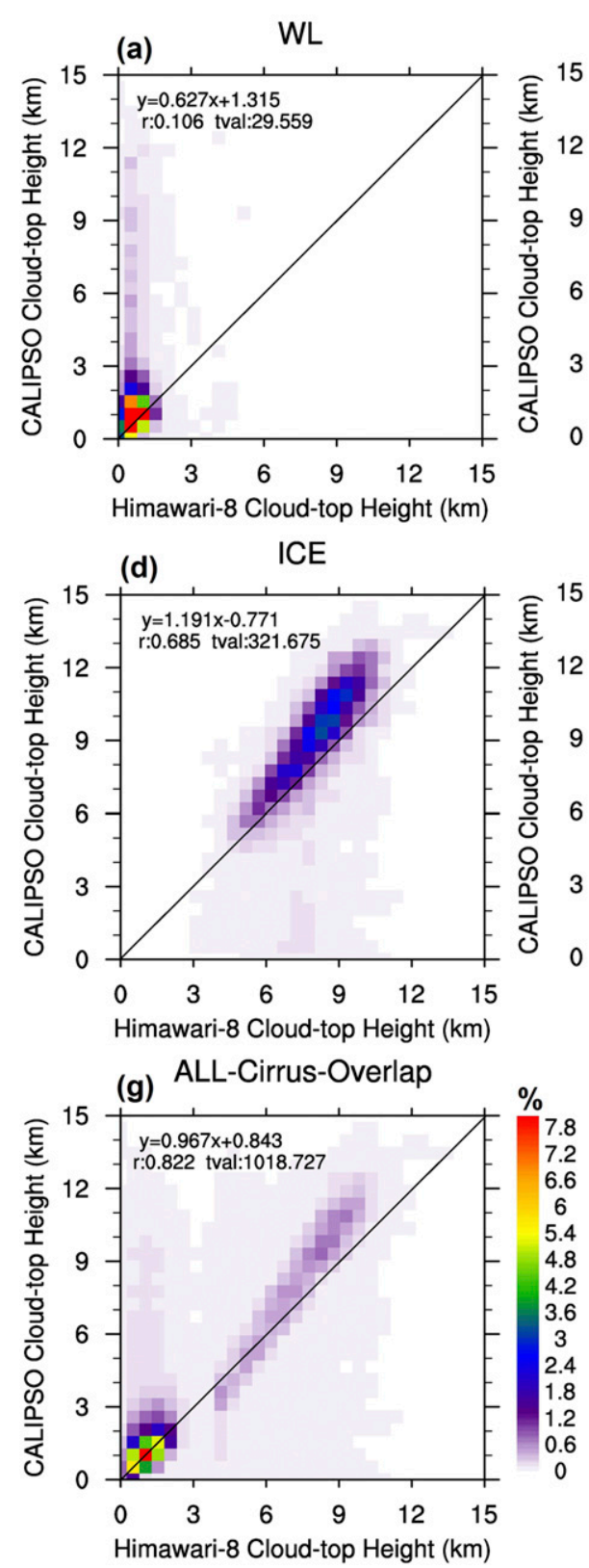
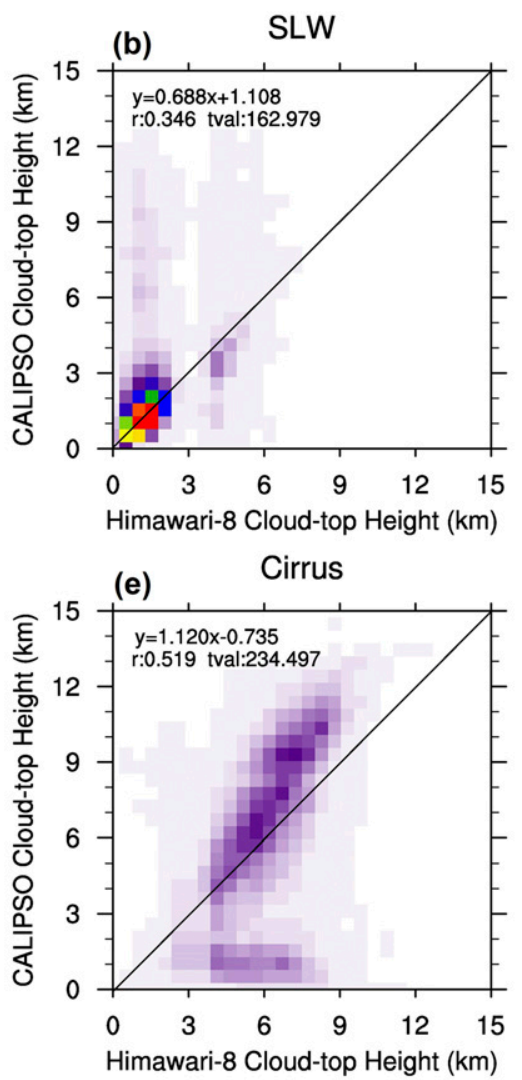
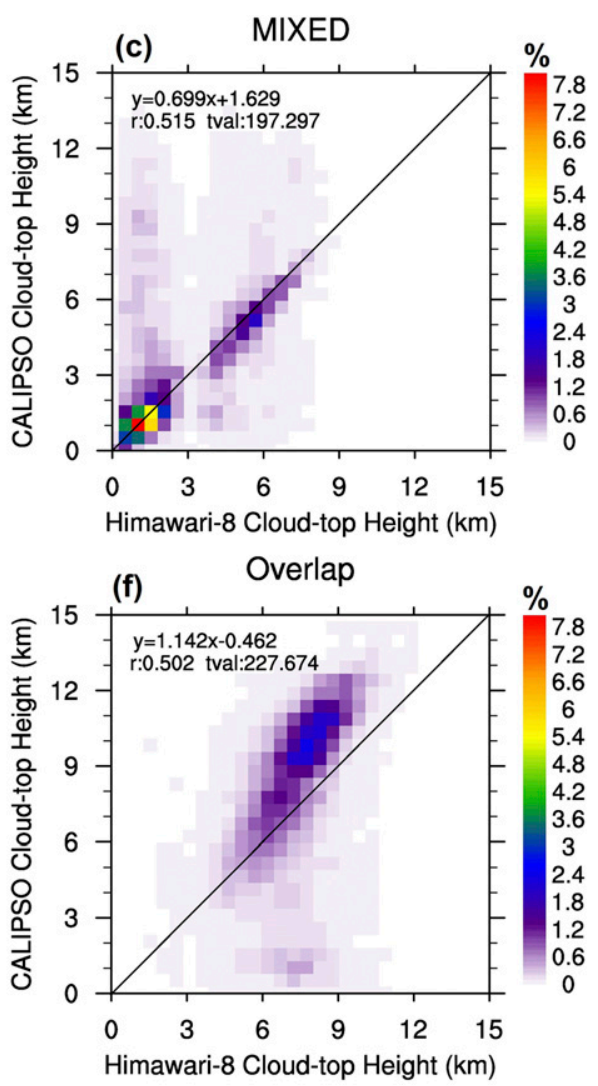

FIG. 5. As in Fig. 3, but evaluated using CALIOP CTH retrievals.

which may be due to the higher sensitivity of the CALIOP lidar to optically thin upper-level clouds (e.g., subvisible cirrus clouds) that are undetected by Himawari-8. In particular, a general large negative bias is evident for the opaque ICE cloud type, which could be related to the differences of the radiatively effective cloud tops detected by the AHI and visible cloud tops detected by CALIOP. The ACHA algorithm treats optically thick clouds as opaque bodies. As the measured radiance is emitted from within the upper parts of the cloud, the retrieved CTH detected by the AHI is the radiatively effective altitude; hence, the radiatively effective $\mathrm{CTH}$ is expected to be lower than the $\mathrm{CTH}$ detected by CALIOP. For ALL and ALL-CIRRUSOVERLAP (i.e., all clouds with CIRRUS and OVERLAP excluded) clouds, a mode is present around $0 \mathrm{~km}$. A mode is also evident for WL and SLW, but less identifiable for other cloud types. CIRRUS and OVERLAP types feature the most widespread bias distributions, with notable tails on the positive (negative) side when compared with CAPRICORN (CALIOP) observations. The PDFs for the CTT biases (not shown) confirm the results for CTH. Most of the biases are constrained within $\pm 10^{\circ} \mathrm{C}$, with 

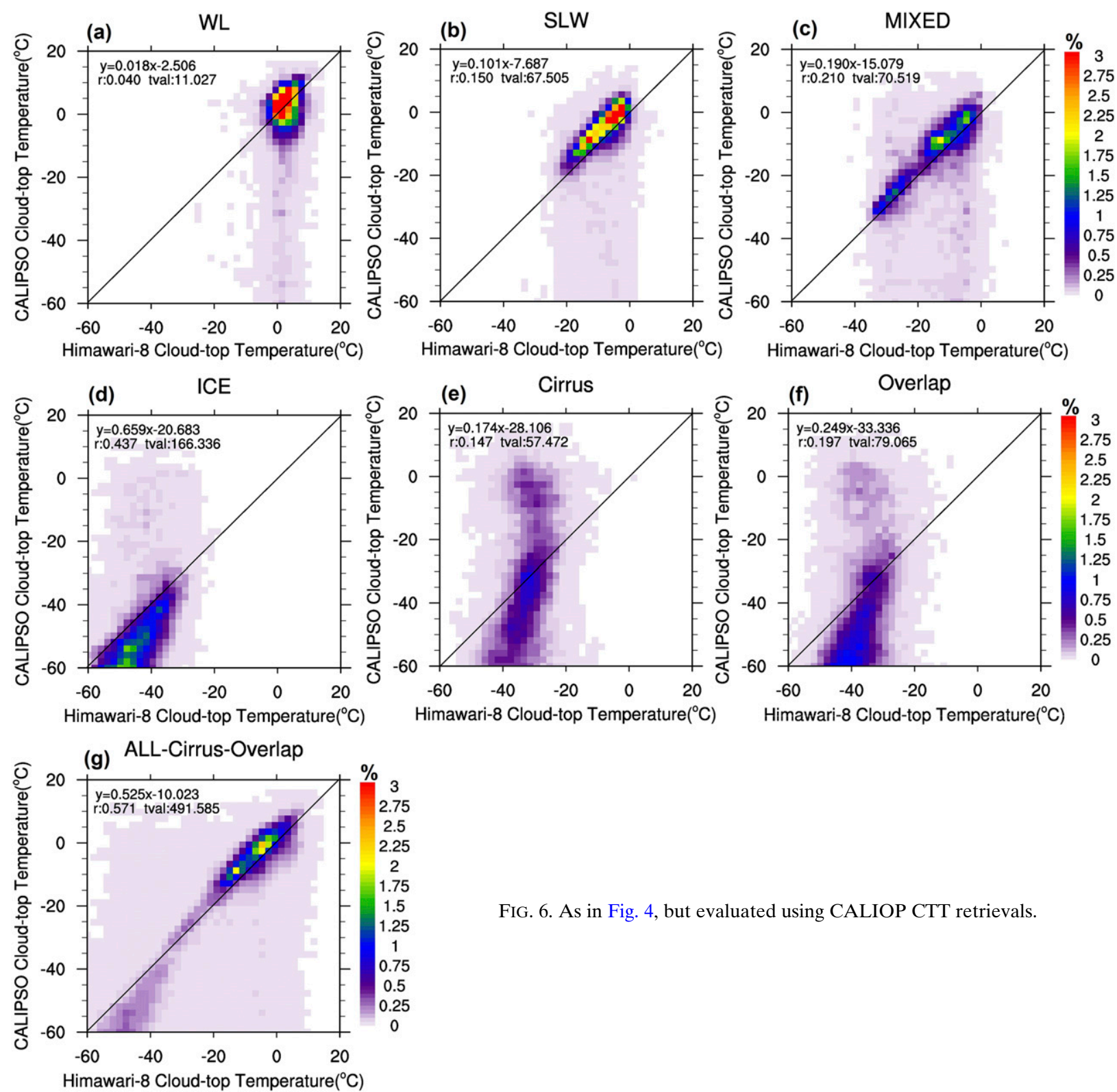

FIG. 6. As in Fig. 4, but evaluated using CALIOP CTT retrievals.

the SLW and MIXED cloud types being best constrained. In addition, both the comparisons with CAPRICORN and CALIOP indicate a cold bias for SLW type (as measured by the quartiles and mean biases), suggesting that the Himawari-8 CTT has a systematic cold bias for SLW cloud type.

To summarize, the major systematic biases identified for the Himawari-8 CTH and CTT retrievals in comparison with the shipborne (CAPRICORN) and spaceborne (CALIOP) retrievals are as below:

- a low (warm) bias in CTH (CTT) for WL cloud type,

- a cold bias in CTT for SLW cloud type,
- a lack of CTH at $\sim 3 \mathrm{~km}$ that does not have a corresponding gap in CTT,

- a tendency of misclassifying some low- and mid-top clouds as CIRRUS and OVERLAP types, and

- a saturation of CTH $(\mathrm{CTT})$ around $10 \mathrm{~km}\left(-40^{\circ} \mathrm{C}\right)$, primarily for CIRRUS and OVERLAP cloud types.

\section{Discussion}

\section{a. Parallax issue}

As briefly noted in section 3, a common issue that complicates the analysis of geostationary satellite 
(c) Himawari-8 CTH (0500UTC July 02, 2016)
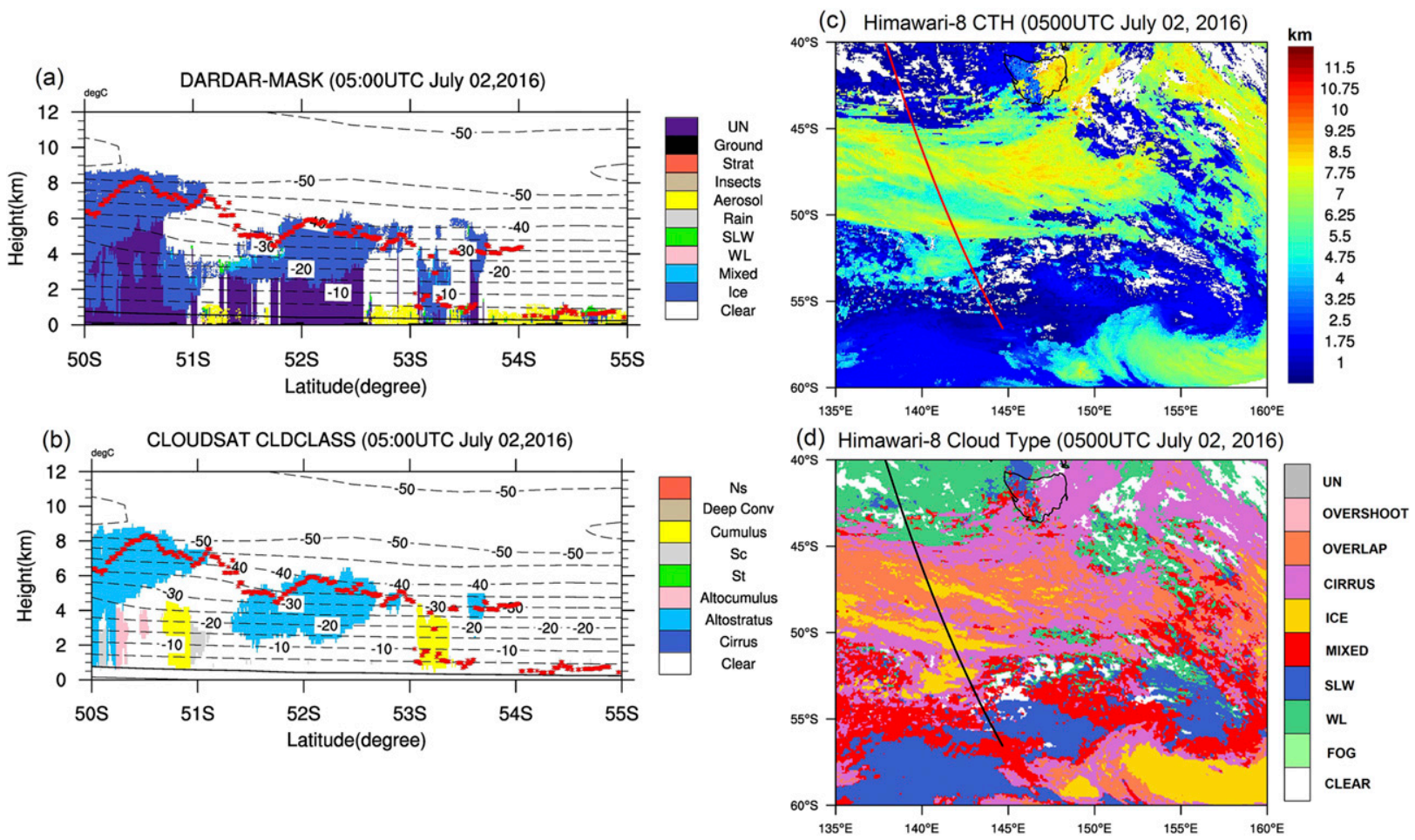

FIG. 7. An example of cloud property retrievals from A-Train satellites and Himawari-8 at approximately 0500 UTC 2 Jul 2016. (a) Cross-section of the cloud and aerosol mask from the DARDAR-MASK, overlaid with ECMWF temperatures and collocated Himawari-8 CTHs; (b) as in (a) but for CloudSat-only cloud classification; (c) Himawari-8 cloud top heights overlaid with A-Train ground track; and (d) Himawari-8 cloud type with A-Train ground track. The red asterisks in (a) and (b) indicate the corresponding Himawari-8 cloud top heights.

observations is the parallax displacement. While this is a problem of little importance on the synoptic scale, it may play a major role for the mesoscale and storm scale systems away from the subsatellite point (north-south and west-east), and is larger for higher clouds. Therefore, although the operational Himawari-8 production does not take this factor into account, we performed an independent postcorrection to the total number of the 10-min Himawari- 8 samples to assess any impact that parallax displacement may have on the biases identified with the ship-based observations. To do this we employ the method proposed in Vicente et al. (2002) where the correction is determined by the derived CTH, the apparent position of the observed cloud, and the position of the satellite. The correction was performed to all the Himawari-8 cloud samples during CAPRICORN.

The PDFs of the shifts in latitudes and longitudes for the evaluated cloud samples are presented in Fig. 9. Overall, the changes in longitude are negligible, with all the samples shifted within $0.045^{\circ}$. The changes in latitude are larger, with $95 \%$ of the samples shifted within $0.192^{\circ}$. Using the "corrected" positions of the Himawari-8 CTHs and CTTs, the comparisons with the ship-based counterparts are repeated (Table 5). In general, however, little improvement is found, as shown by the correlation coefficient of $0.831(0.810)$, mean bias error of $0.193 \mathrm{~km}$ $\left(-2.250^{\circ} \mathrm{C}\right)$, and an RMSE of $1.726 \mathrm{~km}\left(10.423^{\circ} \mathrm{C}\right)$ for CTH (CTT). Some slight improvements are found for the OVERLAP type, while the results for the other types are somewhat degraded. Overall, the general error characteristics remain largely unchanged. This result suggests that the parallax issue cannot explain the large biases identified for the multilayer, high-top cloud types. The correction can, however, potentially mask important features that are occurring at the low levels, where the parallax error is minimal.

\section{b. Low clouds}

The poor consistencies in the CTH and CTT for the WL and SLW cloud types are worrisome, as these cloud types are ubiquitous and have a strong cooling effect to the planet. Given that these clouds generally feature the lowest CTHs that primarily reside in the lowest $3 \mathrm{~km}$, the biases may lie in the inherent difficulties for the infrared-based spaceborne measurements 
(a) CTH Bias PDF (All)

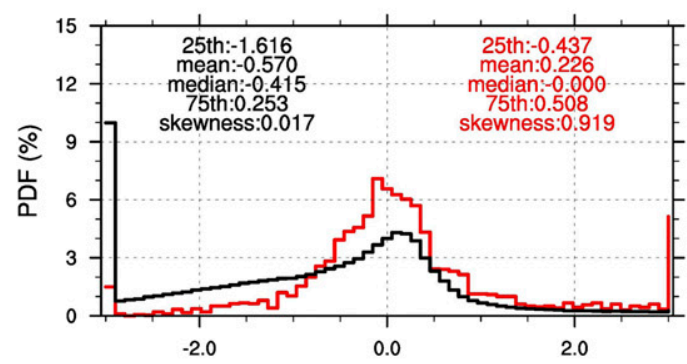

(c) CTH Bias PDF (Warm Liquid)

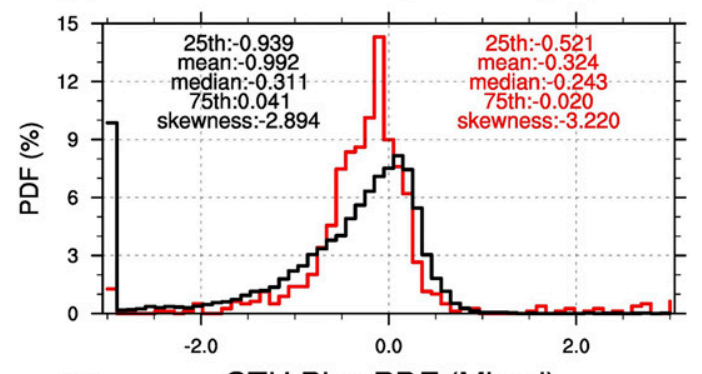

(e) $\quad$ CTH Bias PDF (Mixed)

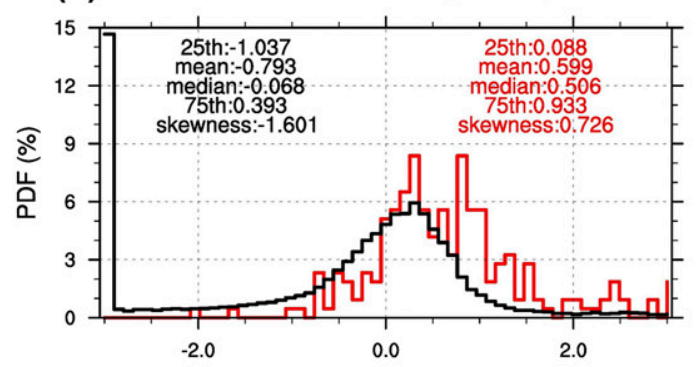

(g) $\quad$ CTH Bias PDF (Cirrus)

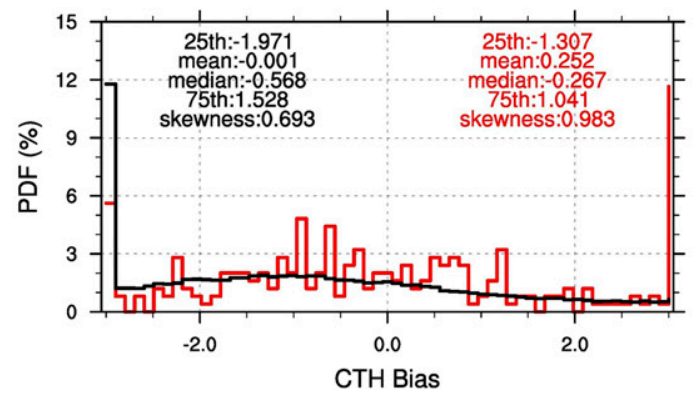

(b) CTH Bias PDF (All-Cirrus-Overlap)
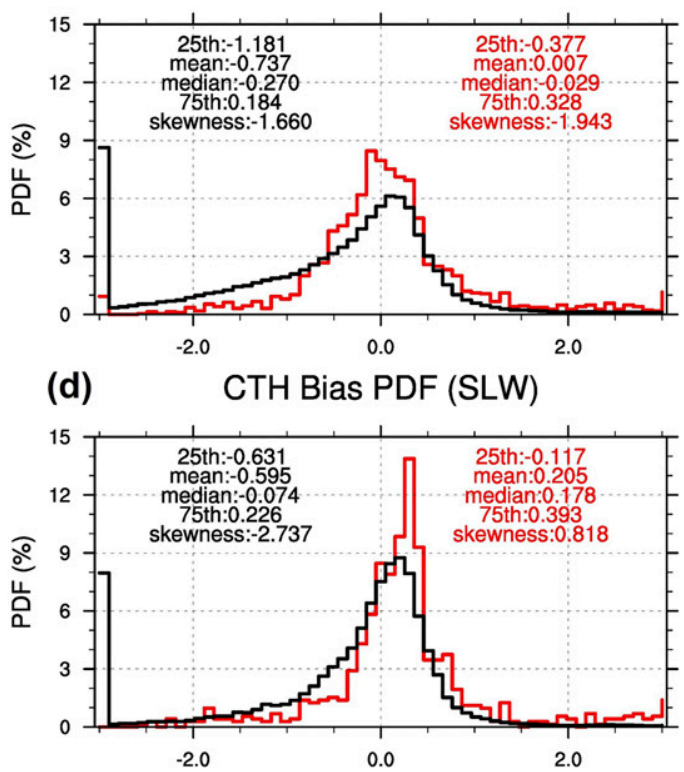

(f) $\quad$ CTH Bias PDF (Ice)

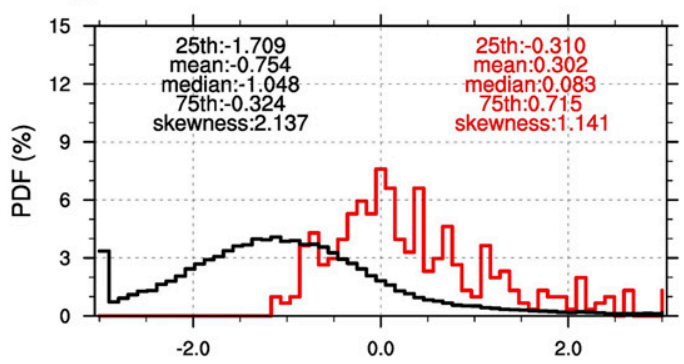

(h) $\quad$ CTH Bias PDF (Overlap)

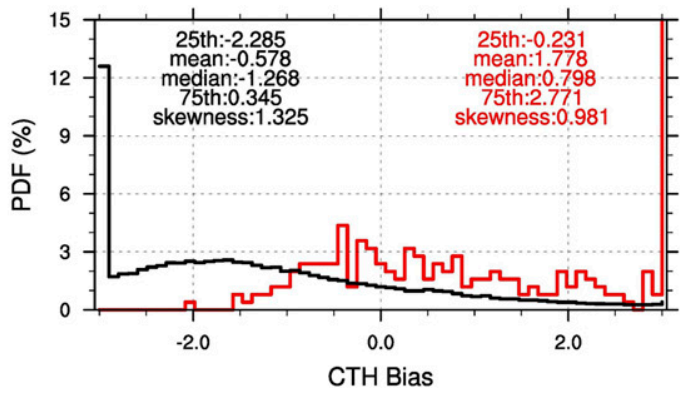

FIG. 8. Probability density function (PDF) plots for the Himawari-8 CTH biases for different cloud types evaluated by the shipborne estimates. Results from CAPRICORN-2016 (CALIOP) are shown in red (black).

in detecting low clouds due to the uncertainties in the assumed temperature and water vapor profiles in the lower atmosphere, especially within the boundary layer. Another potential source of errors may trace to the ACCESS NWP temperature profiles that have difficulties in accurately representing any low-level inversion, which subsequently affect the Himawari-8 CTH retrievals. The latter issue may be even more pertinent for the SLW CTH retrievals, as shown by a larger spread in the frequency diagram. Currently two separate methods are applied in the ACHA (Heidinger 2011), as similarly handled by the MODIS algorithms, depending on whether the cloud is across an inversion (as determined by the NWP temperature profiles). When a cloud temperature is found to reside outside of an inversion, a simple linear interpolation is used to estimate CTH. Alternatively, if any layer (water-phase clouds over the water 

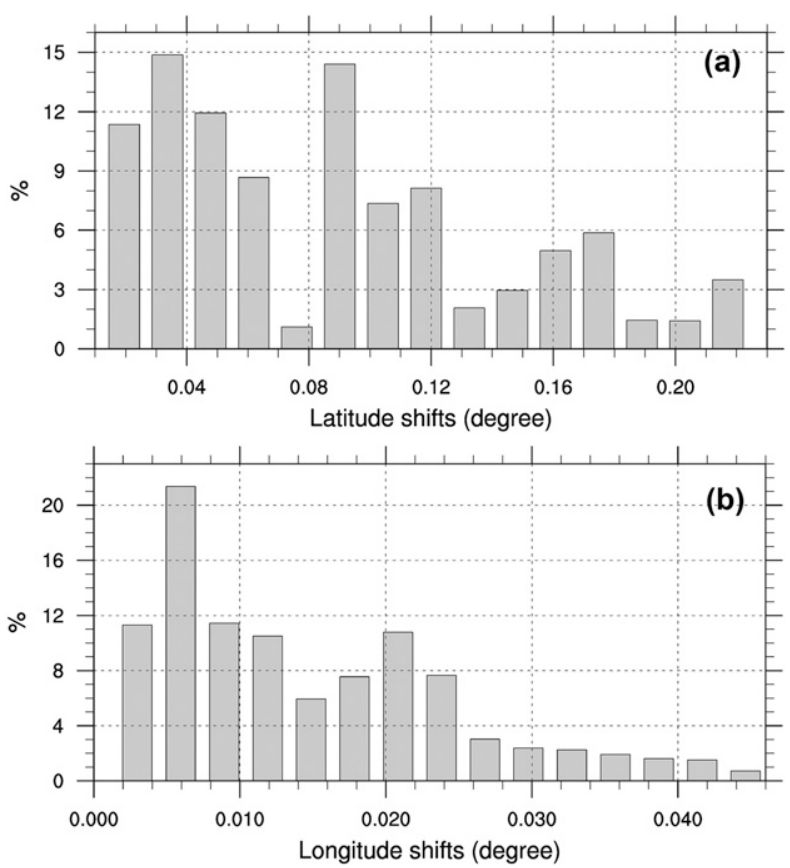

FIG. 9. PDF plots of Himawari-8 cloud position shifts after a parallax correction. (a) Cloud position shifts in latitude; (b) cloud position shifts in longitude.

only) between 700 and $50 \mathrm{hPa}$ above the surface is found to be warmer than the layer below it, the clouds are assumed to reside across an inversion in which case the $\mathrm{CTH}$ is estimated by dividing the difference between the cloud temperature and the surface temperature by a predefined lapse rate $\left(-9.8 \mathrm{~K} \mathrm{~km}^{-1}\right.$ is used in the current scheme). Despite the Himawari-8 cloud product itself, it should be noted that different models with various resolutions are used to produce the temperature profiles needed for the different products. Therefore, uncertainties associated with the spread among the modeled temperature profiles cannot be completely ruled out. The CTT comparison presented in this study is between Himawari-8 CTT retrievals and model temperatures at cloud-top levels. Thus, the CTT differences should not be equated to retrieval errors, particularly for low clouds where model representations of the temperature profiles are prone to large biases. In addition to NWP models, it is possible to get more accurate boundary layer heights using the lapse rate technique by assuming a lapse rate that accounts for the cloud temperature change with height. Some recent studies have demonstrated the usefulness of this technique using CALIOP and MODIS observations (Sun-Mack et al. 2014) as well as aircraft data and GOES-10 retrievals (Painemal et al. 2013).

\section{c. Overlap scenario}

The OVERLAP cloud type, which is characterized by the largest inconsistencies in the intercomparisons, is challenging. These clouds feature some of the most inhomogeneous conditions, posing challenges to both the passive and active sensors. To examine this scenario, a contingency table (Table 6) is produced where the 1-min ship-based cloud cover type within each 10-min averaging window is examined against the corresponding Himawari-8 cloud type. Overall, only $\sim 22 \%$ of the Himawari-8 OVERLAP scenes have 100\% 1-min multilayer profiles according to the ship measurements; $153 / 60 \%(100 / 40 \%)$ of the Himawari-8 OVERLAP scenes have at least $1 \mathrm{~min}(5 \mathrm{~min})$ of the ship-based multilayer type within the 10-min window. On the other hand, $2448 / 93 \%$ of the Himawari-8 non-OVERLAP scenes have $100 \%$ nonmultilayer profiles according to the shipborne measurements. Approximately 807/30\% $(377 / 14 \%)$ of the Himawari-8 non-OVERLAP scenes have at least $1 \mathrm{~min}(5 \mathrm{~min})$ of the ship-based multilayer type within the 10-min window. These results indicate that the ship-based and Himawari-8 nonOVERLAP scenarios agree reasonably well, while the OVERLAP type assigned by the Himawari-8 algorithm is complicated by large heterogeneity of the actual cloud field, making a direct comparison and hence a quantitative estimate of the CTH/CTT biases much more difficult.

TABLE 5. Parallax-corrected CTHs and CTTs.

\begin{tabular}{|c|c|c|c|c|c|c|c|c|c|c|}
\hline & \multicolumn{5}{|c|}{$\mathrm{CTH}$} & \multicolumn{5}{|c|}{ CTT } \\
\hline & Counts (\%) & $r$ & Bias & RMSE & $\sigma$ & Counts (\%) & $r$ & Bias & RMSE & $\sigma$ \\
\hline All & $3083(100 \%)$ & 0.831 & 0.193 & 1.726 & 2.981 & $3056(100 \%)$ & 0.810 & -2.250 & 10.423 & 108.666 \\
\hline All-Cirrus-Overlap & $2288(77.5 \%)$ & 0.903 & 0.013 & 1.142 & 1.305 & $2288(77.2 \%)$ & 0.894 & -1.544 & 6.854 & 47.004 \\
\hline WL & $812(31.7 \%)$ & 0.064 & -0.382 & 1.180 & 1.395 & $815(31.4 \%)$ & 0.146 & 1.203 & 7.160 & 51.327 \\
\hline SLW & $731(25.3 \%)$ & 0.658 & 0.218 & 0.870 & 0.758 & $743(25.5 \%)$ & 0.798 & -4.446 & 3.348 & 11.227 \\
\hline Mixed & $215(9.7 \%)$ & 0.937 & 0.574 & 0.829 & 0.690 & $221(10.0 \%)$ & 0.857 & -4.274 & 4.869 & 23.816 \\
\hline Ice & $304(10.8 \%)$ & 0.836 & 0.267 & 0.917 & 0.845 & $289(10.3 \%)$ & 0.537 & -1.606 & 6.477 & 42.096 \\
\hline Cirrus & $223(9.4 \%)$ & 0.414 & 0.177 & 2.736 & 7.519 & $212(9.6 \%)$ & 0.154 & 0.144 & 17.106 & 294.006 \\
\hline Overlap & 268 (11.3\%) & 0.038 & 1.698 & 2.612 & 6.850 & 258 (11.1\%) & 0.190 & -10.914 & 15.932 & 254.828 \\
\hline
\end{tabular}


TABLE 6. Contingency table where the CAPRICORN ship-based cloud cover type within each 10-min averaging window is compared against the corresponding Himawari-8 cloud type.

\begin{tabular}{lcc}
\hline \hline & Himawari-8 (yes) & Himawari-8 (no) \\
\hline Ship (yes) & $153,137,125,115,100,89,79,75,64,56$ & $807,627,500,424,377,290,257,237,216$, \\
Ship (no) & $99,115,127,137,152,163,173,177,188$, & $1825,2005,2132,2208,2255,2342,2375$, \\
& 196 & $2395,2416,2448$ \\
Minimum number of & $1,2,3,4,5,6,7,8,9,10$ \\
$\quad$ ship-based 1-min profiles considered & & \\
within the 10-min window
\end{tabular}

\section{d. Sensitivity to optical thickness}

Similar to other passive spaceborne sensors, AHI's detection efficiency is expected to decrease at lower optical depths, therefore it is useful to examine the $\mathrm{CTH}$ and CTT biases against CALIOP as a function of COT retrieved by Himawari-8. Figure 10 shows the statistics of the Himawari-8 CTH bias compared against CALIOP, which are calculated for bins containing comparable sizes of coincident observations (i.e., $15000 \pm 3000$ per bin). Overall, the results show a discernible reduction in the error spread (as seen in the 5th and 95th percentiles and quartiles) as COT increases, but becomes more constant when COT exceeds 10. The median CTH bias is also generally reduced with increasing COT. For CTT, however, the sign of the median bias changes from positive to negative when COT exceeds 7 , showing a consistent pattern as seen in Fig. 1d. In general, the differences between the CALIOP and Himawari-8 CTH and CTT tend to reduce as the COT becomes sufficiently large.

\section{Conclusions}

Cloud-top height (CTH) and cloud-top temperature (CTT) retrieved from the Himawari-8 observations

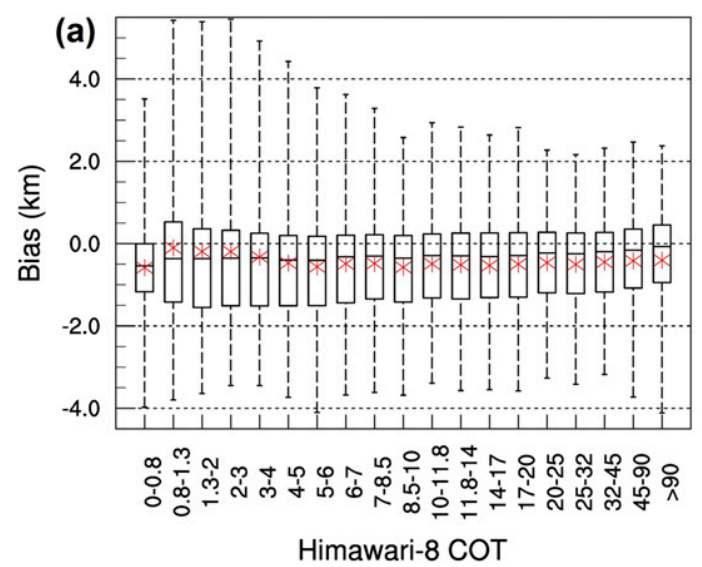

using the ABI Cloud Height Algorithm (ACHA) are evaluated using the active shipborne radar-lidar observations derived from the Clouds, Aerosols, Precipitation Radiation and Atmospheric Composition over the Southern Ocean (CAPRICORN) Phase I experiment in 2016 and 1-yr observations from the spaceborne CloudAerosol Lidar with Orthogonal Polarization (CALIOP) cloud product over the Southern Ocean region $\left(43^{\circ}-60^{\circ} \mathrm{S}\right.$, $\left.135^{\circ}-160^{\circ} \mathrm{E}\right)$. The Himawari- 8 cloud type product, which is based on four AHI infrared channels, is also used to help identify the origin of the retrieval biases.

The basic statistics from the shipborne observations show that low clouds $(\mathrm{CTH}<3 \mathrm{~km})$ dominated the sampled population, occurring $65 \%$ of the time. Midtop clouds $(3 \mathrm{~km} \leq \mathrm{CTH} \leq 6 \mathrm{~km})$ presented $14 \%$ of the time while high-top clouds ( $\mathrm{CTH}>6 \mathrm{~km}$ ) were observed $21 \%$ of the time over the SO. The statistics using $1-\mathrm{yr}$ CALIOP observations suggest an overall consistent picture, but higher frequencies of both the mid-top and high-top clouds were recorded. These differences are likely a result of sampling bias, primarily on the mixedphase and supercooled clouds, presumably due to the different sampling periods and geographical regions.

Results of the comparisons show that the Himawari-8 CTH (CTT) retrievals agree reasonably well with the

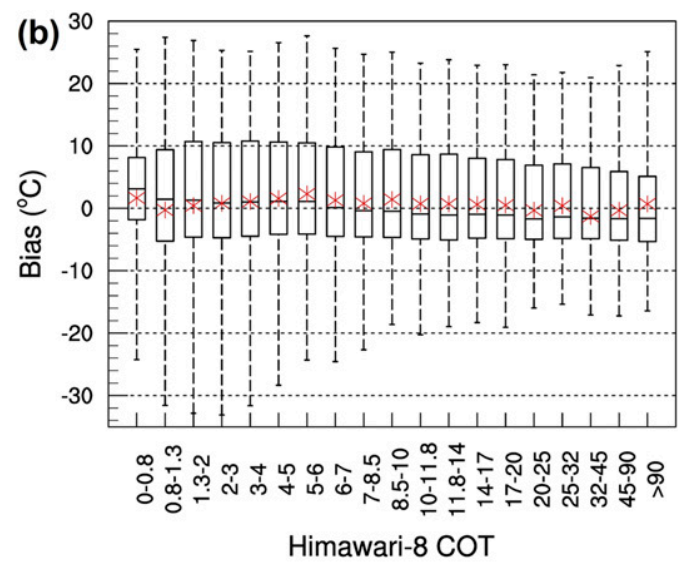

FIG. 10. Statistics of the Himawari-8 (a) CTH and (b) CTT biases evaluated by CALIOP retrievals as a function of COT retrieved by Himawari-8. Red asterisks indicate the mean values. 
shipborne estimates, with a correlation coefficient of $0.837(0.820)$, a mean bias error of $0.226 \mathrm{~km}\left(-2.526^{\circ} \mathrm{C}\right)$, and an RMSE of $1.684 \mathrm{~km}\left(10.069^{\circ} \mathrm{C}\right)$, respectively. When compared with CALIOP CTH (CTT), the corresponding correlation coefficient, mean bias error, and RMSE are found to be $0.786(0.480),-0.570\left(1.343^{\circ} \mathrm{C}\right)$, and $2.297 \mathrm{~km}\left(25.176^{\circ} \mathrm{C}\right)$. These differences suggest that the Himawari- $8 \mathrm{CTH}$ and CTT retrievals primarily fall between the estimates using surface-based and spaceborne active remote sensors, as would be expected.

Despite the general agreement, the major systematic biases identified in this study are

- a low (warm) bias in CTH (CTT) for WL cloud type, - a cold bias in CTT for SLW cloud type,

- a lack of CTH at $\sim 3 \mathrm{~km}$ that does not have a corresponding gap in CTT,

- a tendency of misclassifying some low-/mid-top clouds as CIRRUS and OVERLAP types, and

- a saturation of CTH (CTT) around $10 \mathrm{~km}\left(-40^{\circ} \mathrm{C}\right)$, particularly for CIRRUS and OVERLAP cloud type.

In general, the retrieval accuracy is increased for single-layer, optically thick clouds, but it deteriorates for warm (boundary layer) clouds, cirrus, and multilayer clouds. The low accuracy for boundary layer cloud retrievals can be due, in part, to the limited vertical resolution of the assumed temperature profiles from the NWP model in combination with the presence of temperature inversions, as discussed in other studies with different passive satellite products (e.g., Baum et al. 2012; Holz et al. 2008). Moreover, some low cloud regimes, such as cumulus, are broken in nature. As such, the measured signal is also influenced by both the cloud fraction and the surface, which further contribute to the uncertainties. Other sources of uncertainties, including the potential influence of undetected aerosols and thin cloud above the boundary layer on the small clearcloudy radiance differences, are discussed in Hamann et al. (2014). Note that although some of these issues are known and many research groups have developed methods tackling these challenges, all of the approaches must be individually calibrated to provide optimal results for the CTH retrievals. As such, this issue remains a subject of ongoing investigations.

Retrieving the CTH and CTT are particularly challenging for CIRRUS and OVERLAP cloud types. These large biases cannot simply be explained by any parallax displacement (which is not corrected in the operational product). Although errors in the ship-based and CALIOP estimates due to interpolations from the relatively coarse vertical resolutions of ERA-Interim and GEOS-5 temperature profiles may be a contributing factor, it seems that the ACHA algorithm has a tendency of misclassifying some lower cloud signals (or perhaps even clear sky conditions) as CIRRUS or OVERLAP types. The exact causes of these errors remain elusive, but the misclassification may exacerbate the uncertainties of cloud remote sensing even more, particularly for deep convective and corresponding deep outflow (anvil and cirrus) clouds, with a lack of information related to their longwave cloud forcing that is strongly dependent on CTT. The radiative effect of these uncertainties can be significant compared to the cloud effect itself and, therefore, other retrieved cloud properties may also be uncertain. A better understanding of this issue is a subject for future work.

Finally, the retrieval uncertainty for optically thin clouds is generally greater than for optically thick clouds, although the error characteristics of CTH and CTTs behave differently. Uncertainties in the retrievals of optically thin clouds arise not only from the assumed water vapor profiles, surface temperature and emissivity, but also from instrument noise, spectral response function and errors in the radiative model approximations (Menzel et al. 2008).

This study targets a large sector of the remote SO where field observations that can be used to validate satellite products are sparse, and challenging conditions (e.g., mixed-phase/supercooled clouds and high solar zenith angle) are commonly encountered. However, the findings of this study may be relevant to broader geographical regions where similar meteorology and cloud regimes occur. Although only one retrieval product is evaluated, this study contributes to the continuing effort to improve the understanding of passive satellite retrieval biases and to facilitate the effective use of retrieval datasets for the validation of weather and climate models. Our results also provide guidance for future studies where Himawari cloud retrievals produced by other groups using independent algorithms may also be assessed.

Acknowledgments. This work is supported by the Australian Research Council Discovery Project DP150102894. The authors wish to thank the CSIRO Marine National Facility for its grant of sea time on Investigator and associated personnel, scientific equipment, and data management.

\section{REFERENCES}

Baum, B. A., W. P. Menzel, R. A. Frey, D. C. Tobin, R. E. Holz, S. A. Ackerman, A. K. Heidinger, and P. Yang, 2012: MODIS cloud top property refinements for Collection 6. J. Appl. Meteor. Climatol., 51, 1145-1163, https://doi.org/10.1175/JAMC-D-11-0203.1.

Benas, N., S. Finkensieper, M. Stengel, G.-J. van Zadelhoff, T. Hanschmann, R. Hollmann, and J. F. Meirink, 2017: The MSG-SEVIRI-based cloud property data record CLAAS-2. 
Earth Syst. Sci. Data, 9, 415-434, https://doi.org/10.5194/ essd-9-415-2017.

Bennartz, R., 2007: Global assessment of marine boundary layer cloud droplet number concentration from satellite. J. Geophys. Res., 112, D02201, https://doi.org/10.1029/2006JD007547.

Bouniol, D., and Coauthors, 2010: Using continuous ground-based radar and lidar measurements for evaluating the representation of clouds in four operational models. J. Appl. Meteor. Climatol., 49, 1971-1991, https://doi.org/10.1175/2010JAMC2333.1.

Chahine, M. T., 1974: Remote sounding of cloudy atmospheres. I. The single cloud layer. J. Atmos. Sci., 31, 233-243, https:// doi.org/10.1175/1520-0469(1974)031<0233:RSOCAI >2.0.CO;2.

Dee, D. P., and Coauthors, 2011: The ERA-Interim reanalysis: Configuration and performance of the data assimilation system. Quart. J. Roy. Meteor. Soc., 137, 553-597, https://doi.org/ 10.1002/qj.828.

Delanoë, J., and R. J. Hogan, 2010: Combined CloudSat-CALIPSOMODIS retrievals of the properties of ice clouds. J. Geophys. Res., 115, D00H29, https://doi.org/10.1029/2009JD012346.

— radar for cloud and fog studies. J. Atmos. Oceanic Technol., 33, 1023-1038, https://doi.org/10.1175/JTECH-D-15-0104.1.

Grise, K. M., L. M. Polvani, and J. T. Fasullo, 2015: Reexamining the relationship between climate sensitivity and the Southern Hemisphere radiation budget in CMIP models. J. Climate, 28, 9298-9312, https://doi.org/10.1175/JCLI-D-15-0031.1.

Hamann, U., and Coauthors, 2014: Remote sensing of cloud top pressure/height from SEVIRI: Analysis of ten current retrieval algorithms. Atmos. Meas. Tech., 7, 2839-2867, https:// doi.org/10.5194/amt-7-2839-2014.

Heidinger, A. K., 2011: ABI cloud height. NOAA NESDIS Center for Satellite Applications and Research Algorithm Theoretical Basis Doc., 77 pp.

Holz, R. E., S. A. Ackerman, F. W. Nagle, R. Frey, S. Dutcher, R. E. Kuehn, M. A. Vaughan, and B. Baum, 2008: Global Moderate Resolution Imaging Spectroradiometer (MODIS) cloud detection and height evaluation using CALIOP. J. Geophys. Res., 113, D00A19, https://doi.org/10.1029/2008JD009837.

Hu, Y., S. Rodier, K. Xu, W. Sun, J. Huang, B. Lin, P. Zhai, and D. Josset, 2010: Occurrence, liquid water content, and fraction of supercooled water clouds from combined CALIOP/IIR/ MODIS measurements. J. Geophys. Res., 115, D00H34, https:// doi.org/10.1029/2009JD012384.

Huang, Y., S. T. Siems, M. J. Manton, L. B. Hande, and J. M. Haynes, 2012a: The structure of low-altitude clouds over the Southern Ocean as seen by CloudSat. J. Climate, 25, 2535-2546, https://doi.org/10.1175/JCLI-D-11-00131.1.

,,$---\ldots$, A. Protat, and J. Delanoë, 2012b: A study on the low-altitude clouds over the Southern Ocean using the DARDAR-MASK. J. Geophys. Res., 117, D18204, https:// doi.org/10.1029/2012JD017800.

— servations of maritime mid-latitude storm-track cloud systems: Comparing the Southern Ocean against the North Atlantic. J. Climate, 28, 1920-1939, https://doi.org/10.1175/JCLI-D-1400169.1.

, S. T. Siems, M. J. Manton, D. Rosenfeld, R. Marchand, G. M. McFarquhar, and A. Protat, 2016: What is the role of sea surface temperature in modulating cloud and precipitation properties over the Southern Ocean? J. Climate, 29, 7453 7476, https://doi.org/10.1175/JCLI-D-15-0768.1.

Illingworth, A. J., and Coauthors, 2007: Cloudnet: Continuous evaluation of cloud profiles in seven operational models using ground-based observations. Bull. Amer. Meteor. Soc., 88, 883 898, https://doi.org/10.1175/BAMS-88-6-883.

Kniffka, A., M. Lockhoff, M. Stengel, and J. F. Meirink, 2013: Validation Report - SEVIRI cloud products, SAF/CM/DWD/ VAL/SEV/CLD Issue 1, Rev. 1.2. Tech. rep., EUMETSAT Satellite Application Facility on Climate Monitoring, 88 pp.

Liu, Z., and Coauthors, 2009: The CALIPSO lidar cloud and aerosol discrimination: Version 2 algorithm and initial assessment of performance. J. Atmos. Oceanic Technol., 26, 1198-1213, https://doi.org/10.1175/2009JTECHA1229.1.

Mace, G. G., and A. Protat, 2018a: Clouds over the Southern Ocean as observed from the R/V Investigator during CAPRICORN. Part I: Cloud occurrence and phase partitioning. J. Appl. Meteor. Climatol., 57, 1783-1803, https://doi.org/10.1175/ JAMC-D-17-0194.1.

$\longrightarrow$, and $\longrightarrow, 2018$ b: Clouds over the Southern Ocean as observed from the R/V Investigator during CAPRICORN. Part II: The properties of nonprecipitating stratocumulus. J. Appl. Meteor. Climatol., 57, 1805-1823, https://doi.org/10.1175/ JAMC-D-17-0195.1.

- Q. Zhang, M. Vaughan, R. Marchand, G. Stephens, C. Trepte, and D. Winker, 2009: A description of hydrometeor layer occurrence statistics derived from the first year of merged Cloudsat and CALIPSO data. J. Geophys. Res., 114, D00A26, https://doi.org/10.1029/2007JD009755.

McGill, M. J., M. A. Vaughan, C. R. Trepte, W. D. Hart, D. L. Hlavka, D. M. Winker, and R. Kuehn, 2007: Airborne validation of spatial properties measured by the CALIPSO lidar. J. Geophys. Res., 112, D20201, https://doi.org/10.1029/2007JD008768.

Menzel, W., and Coauthors, 2008: MODIS global cloud-top pressure and amount estimation: Algorithm description and results. J. Appl. Meteor. Climatol., 47, 1175-1198, https://doi.org/ 10.1175/2007JAMC1705.1.

Minnis, P., C. R. Yost, S. Sun-Mack, and Y. Chen, 2008: Estimating the top altitude of optically thick ice clouds from thermal infrared satellite observations using CALIPSO data. Geophys. Res. Lett., 35, L12801, https://doi.org/10.1029/2008GL033947.

Painemal, D., P. Minnis, and L. O'Neill, 2013: The diurnal cycle of cloud-top height and cloud cover over the southeastern Pacific as observed by GOES-10.J. Atmos. Sci., 70, 2393-2408, https:// doi.org/10.1175/JAS-D-12-0325.1.

Pavolonis, M. J., 2010: GOES-R Advanced Baseline Imager (ABI) algorithm theoretical basis document for cloud type and cloud phase, version 2.0. NOAA NESDIS Center for Satellite Applications and Research Algorithm Theoretical Basis Doc., 86 pp., https:/www.star.nesdis.noaa.gov/goesr/docs/ ATBD/Cloud_Phase.pdf.

—_, and A. K. Heidinger, 2004: Daytime cloud overlap detection from AVHRR and VIIRS. J. Appl. Meteor., 43, 762-778, https://doi.org/10.1175/2099.1.

Protat, A., E. Schulz, L. Rikus, Z. Sun, Y. Xiao, and M. Keywood, 2017: Shipborne observations of the radiative effect of Southern Ocean clouds. J. Geophys. Res. Atmos., 122, 318-328, https:// doi.org/10.1002/2016JD026061.

Puri, K., and Coauthors, 2013: Implementation of the initial ACCESS numerical weather prediction system. Aust. Meteor. Oceanogr. J., 63, 265-284, https://doi.org/10.22499/2.6302.001.

Reuter, M., W. Thomas, P. Albert, M. Lockhoff, R. Weber, K.-G. Karlsson, and J. Fischer, 2009: The CMSAF and FUB cloud detection schemes for SEVIRI: Validation with synoptic data and initial comparison with MODIS and CALIPSO. J. Appl. Meteor. Climatol., 48, 301-316, https:// doi.org/10.1175/2008JAMC1982.1. 
Rienecker, M. M., and Coauthors, 2008: The GEOS-5 Data Assimilation System-Documentation of versions 5.0.1, 5.1.0, and 5.2.0. Tech. Memo. NASA/TM-2008-104606, Vol. 27, 97 pp., https:// ntrs.nasa.gov/archive/nasa/casi.ntrs.nasa.gov/20120011955.pdf.

Roebeling, R. A., A. J. Feijt, and P. Stammes, 2006: Cloud property retrievals for climate monitoring: Implications of differences between Spinning Enhanced Visible and Infrared Imager (SEVIRI) on METEOSAT-8 and Advanced Very High Resolution Radiometer (AVHRR) on NOAA-17. J. Geophys. Res., 111, D20210, https://doi.org/10.1029/2005JD006990.

_ , H. M. Deneke, and A. J. Feijt, 2008: Validation of cloud liquid water path retrievals from SEVIRI using one year of CloudNET observations. J. Appl. Meteor. Climatol., 47, 206-222, https://doi.org/10.1175/2007JAMC1661.1.

Rodgers, C. D., 2000: Inverse Methods for Atmospheric Sounding: Theory and Practice. Series on Atmospheric, Oceanic and Planetary Physics, Vol. 22, World Scientific, 238 pp.

Royer, P., A. Bizard, L. Sauvage, and L. Thobois, 2014: Validation protocol and intercomparison campaigns with the R-MAN510 aerosol lidar. Proc. 17th Int. Symp. for the Advancement of Boundary-Layer Remote Sensing, Auckland, New Zealand, University of Auckland, https://doi.org/10.13140/2.1.4778.1767.

Sassen, K., and Z. Wang, 2008: Classifying clouds around the globe with the CloudSat radar: 1-year of results. Geophys. Res. Lett., 35, L04805, https://doi.org/10.1029/2007GL032591.

Sherwood, S. C., J. H. Chae, P. Minnis, and M. McGill, 2004: Underestimation of deep convective cloud tops by thermal imagery. Geophys. Res. Lett., 31, L11102, https://doi.org/10.1029/ 2004GL019699.

Stephens, G. L., and Coauthors, 2002: The CloudSat mission and the A-Train: A new dimension of space-based observations of clouds and precipitation. Bull. Amer. Meteor. Soc., 83, 17711790, https://doi.org/10.1175/BAMS-83-12-1771.

Stubenrauch, C. J., S. Cros, A. Guignard, and N. Lamquin, 2010: A 6-year global cloud climatology from the Atmospheric InfraRed
Sounder AIRS and a statistical analysis in synergy with CALIPSO and CloudSat. Atmos. Chem. Phys., 10, 7197-7214, https://doi.org/10.5194/ACP-10-7197-2010.

Sun-Mack, S., P. Minnis, Y. Chen, S. Kato, Y. Yi, S. C. Gibson, P. W. Heck, and D. M. Winker, 2014: Regional apparent boundary layer lapse rates determined from CALIPSO and MODIS data for cloud-height determination. J. Appl. Meteor. Climatol., 53, 990-1011, https://doi.org/10.1175/ JAMC-D-13-081.1.

Taylor, S., P. Stier, B. White, S. Finkensieper, and M. Stengel, 2017: Evaluating the diurnal cycle in cloud top temperature from SEVIRI. Atmos. Chem. Phys., 17, 7035-7053, https://doi.org/ 10.5194/acp-17-7035-2017.

Trenberth, K. E., and J. T. Fasullo, 2010: Simulation of presentday and twenty-first-century energy budgets of the Southern Oceans. J. Climate, 23, 440-454, https://doi.org/10.1175/ 2009JCLI3152.1.

Vaughan, M., and Coauthors, 2009: Fully automated detection of cloud and aerosol layers in the CALIPSO lidar measurements. J. Atmos. Oceanic Technol., 26, 2034-2050, https://doi.org/ 10.1175/2009JTECHA1228.1.

Vicente, G. A., J. C. Davenport, and R. A. Scofield, 2002: The role of orographic and parallax corrections on real time high resolution satellite rainfall rate distribution. Int. J. Remote Sens., 23, 221-230, https://doi.org/10.1080/01431160010006935.

Winker, D. M., C. A. Hostetler, M. A. Vaughan, and A. H. Omar, 2006: CALIOP algorithm theoretical basis document: Part 1: CALIOP instrument, and algorithms overview. NASA Tech. Rep. PC-SCI-202 Part 1, 29 pp., https://www-calipso.larc.nasa.gov/ resources/pdfs/PC-SCI-202.Part1_v2-Overview.pdf.

Wolters, E. L. A., R. A. Roebeling, and A. J. Feijt, 2008: Evaluation of cloud phase retrieval methods for SEVIRI on board Meteosat- 8 using ground-based lidar and cloud radar data. J. Appl. Meteor. Climatol., 47, 1723-1738, https://doi.org/ 10.1175/2007JAMC1591.1. 